\title{
Discovery of ADP-Ribosylation and Other Plant Defense Pathway Elements Through Expression Profiling of Four Different Arabidopsis-Pseudomonas R-avr Interactions
}

\author{
Lori Adams-Phillips, ${ }^{1}$ Jinrong Wan, ${ }^{1}$ Xiaoping Tan, ${ }^{2}$ F. Mark Dunning, ${ }^{1}$ Blake C. Meyers, ${ }^{2,3}$ \\ Richard W. Michelmore, ${ }^{2}$ and Andrew F. Bent ${ }^{1}$ \\ ${ }^{1}$ Department of Plant Pathology, University of Wisconsin-Madison, Madison, WI 53706, U.S.A.; ${ }^{2}$ The Genome Center and \\ Department of Plant Sciences, University of California-Davis, Davis, CA 95616, U.S.A.; ${ }^{3}$ Department of Plant and Soil \\ Sciences, University of Delaware, Newark, DE 19711, U.S.A.
}

Submitted 20 September 2007. Accepted 10 January 2008.

\begin{abstract}
A dissection of plant defense pathways was initiated through gene expression profiling of the responses of a single Arabidopsis thaliana genotype to isogenic Pseudomonas syringae strains expressing one of four different cloned avirulence (avr) genes. Differences in the expression profiles elicited by different resistance $(R)$-avr interactions were observed. A role for poly(ADP-ribosyl)ation in plant defense responses was suggested initially by the upregulated expression of genes encoding NUDT7 and poly(ADP-ribose) glycohydrolase in multiple $R$-avr interactions. Gene knockout plant lines were tested for 20 candidate genes identified by the expression profiling, and Arabidopsis NUDT7 mutants allowed less growth of virulent $P$. syringae (as previously reported) but also exhibited a reduced hypersensitive-response phenotype. Inhibitors of poly(ADP-ribose) polymerase (PARP) disrupted $F L S 2$-mediated basal defense responses such as callose deposition. EIN2 (ethylene response) and IXRI and IXR2 (cellulose synthase) mutants impacted the $F L S 2$-mediated responses that occur during PARP inhibition, whereas no impacts were observed for NPR1, PAD4, or NDR1 mutants. In the expression profiling work, false-positive selection and grouping of genes was reduced by requiring simultaneous satisfaction of statistical significance criteria for each of three separate analysis methods, and by clustering genes based on statistical confidence values for each gene rather than on average fold-change of transcript abundance.
\end{abstract}

Additional keywords: elf18, flg22, flagellin, PARG, Pseudomonas syringae pv. glycinea, P. syringae pv. tomato.

Plant disease resistance is mediated by both preformed defenses and inducible defense responses (Lucas 1998). Effective

Corresponding author: Andrew Bent; E-mail: afb@plantpath.wisc.edu; Telephone: +1.608.265.3034; Fax: +1.608.263.2626.

Current address of J. Wan: Division of Plant Sciences, University of Missouri-Columbia, Columbia, MO 65211, U.S.A.

Current address of B. C. Meyers: Department of Plant and Soil Sciences, University of Delaware, Newark, NJ 19711, U.S.A.

* The $\boldsymbol{e}$-Xtra logo stands for "electronic extra" and indicates that eight supplemental figures and supplemental methods material are published online. disease resistance often can be attributed to plant disease resistance $(R)$ genes whose products elicit defense responses following recognition of the presence of particular effector or avirulence (avr) proteins expressed by pathogens (Dangl and Jones 2001; Jones and Dangl 2006). The diverse array of defense responses controlled by $R$ gene action includes cell wall reinforcement; synthesis of phytoalexin compounds, defense peptides, and antimicrobial enzymes; release of signaling molecules that activate defenses in neighboring and distant cells; and activation of the hypersensitive cell death response (HR) (Dangl and Jones 2001; Lucas 1998; Martin et al. 2003; van Loon et al. 2006). Plants induce some of these same mechanisms of resistance, albeit less strongly, against virulent pathogens or in response to nonpathogenic microbes or microbe-associated molecular patterns (MAMPs) such as flagellin (Alfano and Collmer 2004; Conrath et al. 2006; Jones and Dangl 2006; Zipfel and Felix 2005). It is becoming clear that there is significant interplay between basal defenses, $R$ - $a v r$ triggered defense responses, and defense suppression by pathogens (Bent and Mackey 2007; Chisholm et al. 2006; Shen et al. 2006). In addition, it is likely that many antimicrobial compounds and processes activated as part of the plant defense response remain to be discovered.

The extent to which different $R$-avr interactions activate similar or different defense responses is not completely understood. Individual plants express multiple $R$ genes with specificities for different strains of viruses, bacteria, oomycetes, fungi, nematodes, or insect pests, and individual plant genomes include a few hundred $R$ gene-like sequences (Meyers et al. 2003; Michelmore 2000). Several distinct structural classes of $R$ gene products can be distinguished on the basis of sequence. Most $R$ genes studied to date encode putative intracellular proteins with nucleotide binding site and leucine-rich repeat motifs (NBS-LRR proteins) (Hammond-Kosack and Parker 2003; Jones and Dangl 2006; Meyers et al. 2003). These NBS-LRR proteins can be differentiated into further structural subclasses, which may activate overlapping but distinct plant responses.

Overlaps and distinctions between $R$ and $a v r$ pathways have been supported by mutational studies (Feys and Parker 2000; Glazebrook 2001; Hammond-Kosack and Parker 2003; Martin et al. 2003). Some genes, such as NPRl in Arabidopsis, play a central role in the elicitation of multiple plant defense responses. Others, such as NDR1, EDS1, PBS2, PAD4, and RAR1, 
identify divergence in $R$ gene signaling that correlates with the $R$ gene involved. Different $R$ gene-mediated signal transduction pathways may converge downstream to induce a common set of plant defense responses. Alternatively, the different $R$ gene pathways may utilize some distinct signaling components and induce different defense responses (Eulgem et al. 2004; Sato et al. 2007).

Pseudomonas syringae pathovars, like many other gramnegative bacterial pathogens of plants or animals, use a type III secretion system to deliver virulence effectors into host cells (Alfano and Collmer 2004). When these effector proteins are recognized by $R$ gene-mediated processes, they are defined as $a v r$ gene products. The four $P$. syringae avr genes used in this study (avrRpt2, avrRpm1, avrPphB, and avrRps4) and their cognate Arabidopsis $R$ genes (RPS2, RPM1, RPS5, and RPS4) have been cloned and are known to elicit defense responses in an $R$-avr-dependent fashion (Bent et al. 1994; Debener et al. 1991; Dong et al. 1991; Gassmann et al. 1999; Grant et al. 1995; Hinsch and Staskawicz 1996; Jenner et al. 1991; Mindrinos et al. 1994; Warren et al. 1998; Whalen et al. 1991). These $R$ genes all encode NBS-LRR proteins; RPS2, RPM1, and RPS5 are predicted to have a coiled-coil near the N-terminus and RPS4 has a predicted toll interleukin 1 receptor (TIR) domain. Whole-genome phylogenetic analyses indicate that RPS2, RPM1, and RPS5 are diverse representatives of two of the four major classes of coiled-coil R proteins (Meyers et al. 2003).

Distinct strains of $P$. syringae previously have been used to study plant defense responses. Of these, $P$. syringae pv. tomato strain DC3000 (referred to subsequently as DC3000) is virulent on many genotypes of Arabidopsis as well as tomato and other host species (Cuppels 1986; Whalen et al. 1991). P. syringae pv. glycinea race 4 strain (referred to subsequently as R4) is virulent on soybean but, on Arabidopsis Col-0, it is nonvirulent in that it multiplies poorly and neither causes disease nor elicits an HR (Yu et al. 1998). Despite differences in virulence on Arabidopsis, both DC3000 and R4 can deliver the same $a v r$ gene products and elicit defense responses in Arabidopsis that are mediated by the same $R$-avr pairings. This provides an experimental opportunity to investigate the extent to which host responses are the same or different when the eliciting avr signal is delivered by virulent as opposed to nonvirulent pathogen strains.

To initiate the present study, isogenic $P$. syringae strains and a single genotype of Arabidopsis were used to compare the transcript profiles induced by four different $R$-avr pairings. A limited transcript-profiling experiment was carried out to identify candidate genes for further functional study, rather than to establish definitive expression profiles. Because different statistical tests identified markedly different sets of genes as exhibiting significant changes in transcript level, a conservative data analysis approach was used that relied on multiple statistical tests. For each $R-a v r$ interaction, sets of genes were identified that exhibited consistent upregulation $14 \mathrm{~h}$ after inoculation. Genes upregulated in three or more of the tested $R$ - $a v r$ interactions provided a reproducible candidate gene set. Gene knockouts of 20 candidate genes provided evidence for contributions to plant defense by four of these genes and suggested a role for poly(ADP-ribosyl)ation in plant-pathogen interactions.

\section{RESULTS}

\section{Expression profiling using two isogenic systems for elicitation of four different $\boldsymbol{R}$ - or avr-mediated defense responses.}

We utilized an isogenic system to compare plant responses mediated by four different $R$ genes, resulting in the identification of numerous plant genes that are differentially expressed in response to different $R$-avr interactions. Leaves of Arabidopsis ecotype Col-0 were inoculated with isogenic strains of two pathotypes of $P$. syringae that differed only by the expression of one of four cloned avr genes (avrRpt2, avrRpm1, $a v r P p h B$, or $a v r R p s 4$ ). The four $a v r$ gene products were delivered individually by $P$. syringae pv. tomato strain DC3000 and $P$. syringae pv. glycinea strain R4. As controls, plants were either mock inoculated with solution containing no bacteria, inoculated with the same strain of $P$. syringae carrying the plasmid with no $a v r$ gene, or left untreated. Unless otherwise noted, transcript abundance was analyzed relative to the abundance in mock-inoculated control samples. A low titer of bacterial inoculum $\left(1 \times 10^{5} \mathrm{CFU} / \mathrm{ml}\right)$ was used that, for DC3000, results in symptoms resembling those observed following natural infections. This inoculation titer avoided abnormal mass-activation of defense responses in all cells; however, a corollary is that changes in pathogen-induced gene expression were substantially diluted because many host cells were not in direct contact with pathogen (Turner and Novacky 1974). Leaf samples were harvested $14 \mathrm{~h}$ after pathogen inoculation. The relative levels of approximately 8,300 Arabidopsis gene transcripts were determined using AG1 Affymetrix Arabidopsis Gene Chip arrays.

\section{Different analytical methods produced substantially different results.}

Array data initially were processed and analyzed using the Affymetrix MAS software package. Reproducibility of transcript abundance data between treatment replicates was confirmed but fold-change values derived from comparisons of two treatments were less reproducible (Supplemental Fig. S1). This emphasized the need for statistical analysis methods that extended beyond average fold-change to identify those genes whose transcript level is reproducibly altered.

When we used the data set containing two biological replicates of each treatment to identify genes that exhibit a significant transcript abundance change following any given treatment, different commonly used analytical approaches and software packages identified partially overlapping but substantially different sets of genes (Fig. 1). Genes identified by one data analysis method as having exhibited a significant change in transcript abundance often were not detected as significant by another analysis method. The genes identified by one method were not a subset of those identified by a second method, which might be expected if one analysis method was simply more stringent than another. This implies that both false-positives and false-negatives are frequent when lists of genes with a significant transcript abundance change are generated using common expression profile data analysis methods, as also has been reported by others (discussed below).

\section{Data filtering and grouping based on the intersection of statistical criteria.}

We reduced the false-positive (type I error) selection or grouping of genes by requiring satisfaction across multiple significance criteria such as average fold-change, GeneSpring $P$ value, dChip lower bound of confidence interval for foldchange (LBFC), Affymetrix difference call, and analysis of variance (ANOVA). The complete results of these analyses for all probe sets on the arrays, as well as the raw data for this entire study, are available on the University of California Davis and ArrayExpress websites (cited below).

Data were sorted based on the GeneSpring $P$ value, dChip LBFC, and ANOVA rather than on average transcript abundance fold-change (discussed below and in supplemental data). A master list of genes exhibiting altered transcript abundance in response to at least one $R$-avr interaction compared with 
either mock- or DC3000- (with no $a v r$ transgene) inoculated plants was established (Supplemental Table S1). Induced expression was validated by RNA blot analysis and reverse-transcription polymerase chain reaction (RT-PCR) for a small subset of these genes (Supplemental Fig. S2 and discussed below). Due to the fact that some genes are identified by multiple probe sets, this set of 234 probe sets represents 220 genes.

To group genes into sets that exhibited similar regulation in response to different $R$ - $a v r$ interactions, we established qualitative bins that each encompassed a defined quantitative range of significance values (dChip LBFC and GeneSpring $P$ values). Each transcript initially was marked as increased, decreased, or unchanged for each treatment using the cutoff values that had first been applied in data filtering to generate the 234probe-set master set. The relative reliability of the conclusion (level of statistical significance) was noted by the darkness of the gold or blue shading for increase and decrease, respectively (Fig. 2). Genes then were clustered manually based on the strength of statistical support for the conclusion that transcript abundance changed, rather than basing clustering on the transcript abundance fold-change values.

\section{Transcripts altered by wild-type DC3000 or R4 are} almost all altered by $\mathrm{DC} 3000+a v r$ or $\mathrm{R} 4+a v r$ strains as well.

In general, the $P$. syringae pv. glycinea $\mathrm{R} 4$ strains elicited a much weaker response than the DC3000 strains. Our conservative procedure revealed few or no genes that were elevated by DC3000 or R4 alone (with no avr transgene) compared with the mock control. When a less stringently determined list of 558probe sets was examined, nearly all of the genes detectably activated by virulent DC3000 at $14 \mathrm{~h}$ after infection also were activated by $R$ - $a v r$ interactions (Supplemental Table S2). Consistent with this observation, very few genes were identified whose abundance in an $R$-avr interaction was different from
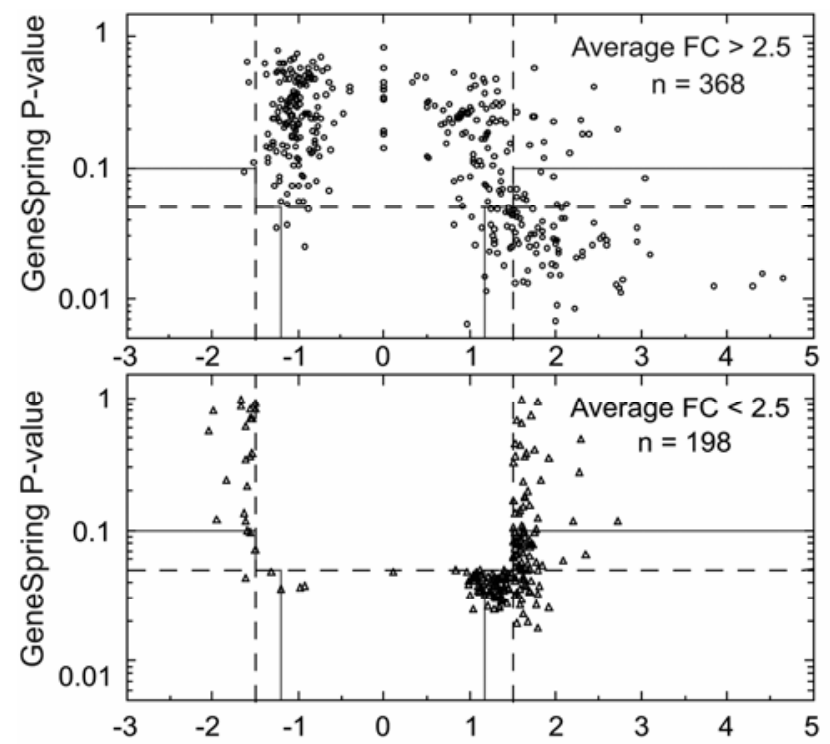

dChip: Lower Bound of Confidence Interval for Fold-Change

Fig. 1. Different software packages identify substantially different sets of 'significant' genes. A representative example is shown, presenting data for transcript levels in plants inoculated with DC3000 avrRpt2 ${ }^{+}$relative to the levels for control mock-inoculated plants from the same experiments. Each data point represents one gene. The upper graph includes all 368 genes that exhibited an average fold-change (for two biological replicates) $\geq 2.5$ as determined by Affymetrix MAS. In the lower graph, genes are presented if they were not already in the upper graph but GeneSpring $P$ value was $<0.05$ or dChip LBFC value was $\geq|1.5|$. Genes were excluded from the figure if $\mid$ AvDiff exp - AvDiff $_{\text {control }} \mid<100$. the abundance during infection with isogenic bacteria lacking a $a v r$ transgene. This is a primary reason why mock-inoculated plants were used as the control in our analyses below. The few genes that were upregulated in three or more $R$-avr interactions compared with DC3000 with no $a v r$ transgene also were identified on our candidate gene list when mock-inoculated plants were used as the control.

\section{Different $R$-avr interactions produce overlapping but distinct expression profiles.}

Our expression profiling study revealed sets of genes within the 220-gene master set that were induced by multiple $R$ - $a v r$ interactions and other sets of genes that were activated by specific $R$-avr interactions. The relative number of genes in each tested $R$-avr interaction that exhibited altered transcript levels $14 \mathrm{~h}$ after inoculation is summarized in Figure 2. In terms of the overall number of genes exhibiting elevated transcript levels, RPS2-avrRpt2 > RPM1-avrRpm1 > RPS5-avrPphB >> RPS4avrRps4. RPS4-avrRps4 interactions produced a minimal response that was more similar to the DC3000 (no $a v r$ ) treatment than it was to the other three $R$ - $a v r$ interactions. This latter result is not surprising given that RPS4 is known to be active but minimally effective in the Col-0 genetic background (Gassmann et al. 1999; Hinsch and Staskawicz 1996; Yu et al. 1998).

Inspection of the data revealed a number of genes for which the statistical test for transcript level change was above the significance cutoff for one or more $R$-avr interactions, yet close to

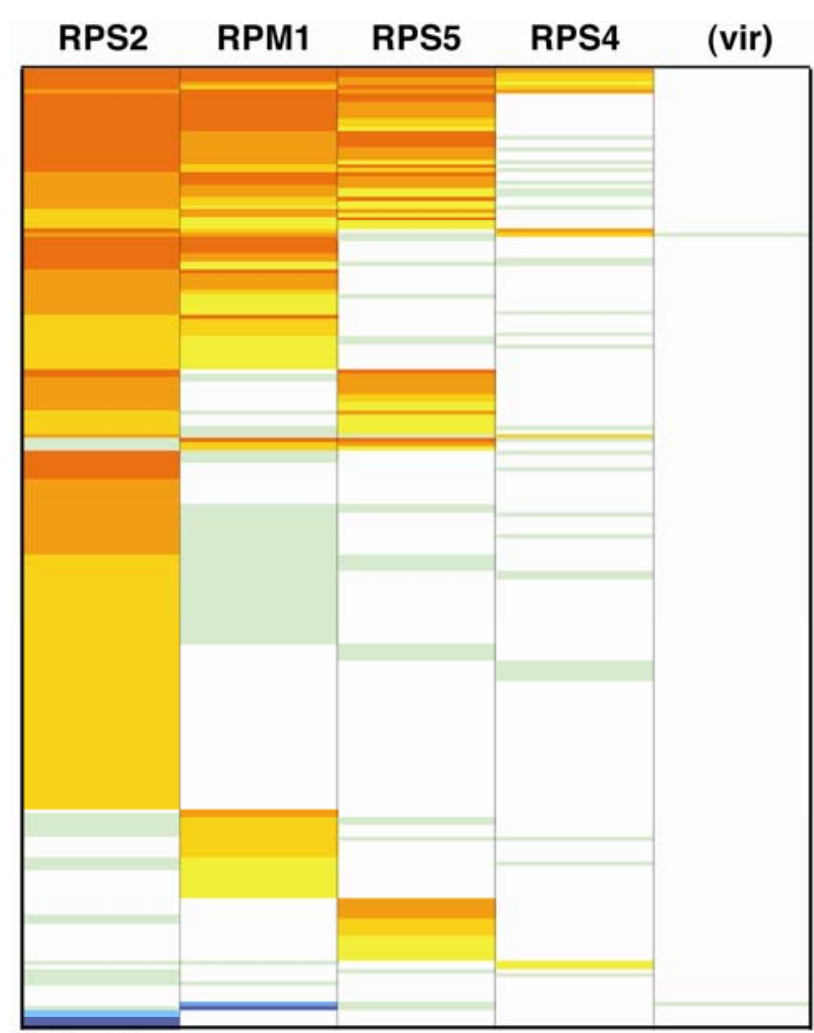

\section{Color Scheme:}

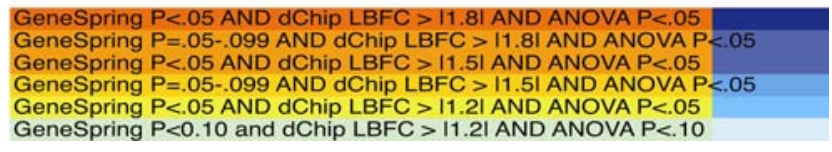

Fig. 2. Extent of co-expression of 234 probe sets that revealed significant upregulation in at least one treatment. Color intensities represent strength of conclusion that the transcript was more (orange) or less (blue) abundant in treatment than in the control, as described in the color key. Vertical height of a colored area reflects the number of genes in that area (figure derived from a vertical list of 234 probe sets). 
but just below the cutoff for another $R$-avr interaction. To reduce type II errors (false characterization of such genes as "differently regulated in the tested $R$ - $a v r$ interactions"), the 220-gene master list was resorted after identifying those genes that satisfied a less stringent cutoff (GeneSpring $P<0.10$ and dChip LBFC $>|1.2|$ for any of the DC3000/mock-inoculation comparisons). The resulting data are presented in Supplemental Table S3. The overall conclusion remained that the different $R$ $a v r$ treatments produced different expression profiles.

\section{Genes upregulated by different $\boldsymbol{R}$-avr interactions include a core set of genes upregulated}

\section{by three or more of the tested $\boldsymbol{R}$-avr interactions.}

In all, 38 genes exhibited elevated transcript levels for three or more $R$-avr interactions tested (Fig. 3). Supplemental Table $\mathrm{S} 4$ is a less stringently defined set of 71 genes that exhibited elevated transcript levels in three or more different DC3000+avr treatments. A number of genes not previously associated with defense were revealed, providing interesting candidates for further study.

\section{Knockout study identifies genes that impact susceptibility to $P$. syringae pv. tomato.}

Of the genes that showed significantly upregulated transcript levels in three or more $R$-avr interactions, those that had not been studied previously with respect to plant-pathogen interactions were targeted for gene knockout experiments. SALK T-DNA insertion Arabidopsis lines were obtained and homozygous mutant lines were generated for the 20 of the 71 genes marked as such. Pathogen growth within leaves then was measured for virulent $P$. syringae pv. tomato DC3000 and for DC3000 expressing avrRpt2. This candidate gene approach yielded four genes for which mutants showed significantly altered susceptibility to virulent DC3000 in multiple independent tests (Supplemental Fig. S3); At4g12720 (NUDT7, encoding a nudix hydrolase), At4g23700 ( $\mathrm{CHX17}$, encoding a cation/H+ exchanger), At4g39950 (CYP79B2, encoding a cytochrome P450), and At4g29740 (CKX4, encoding a cytokinin oxidase). Overall, roles in plant disease resistance cannot be ruled out for the other genes that were mutationally tested;
A

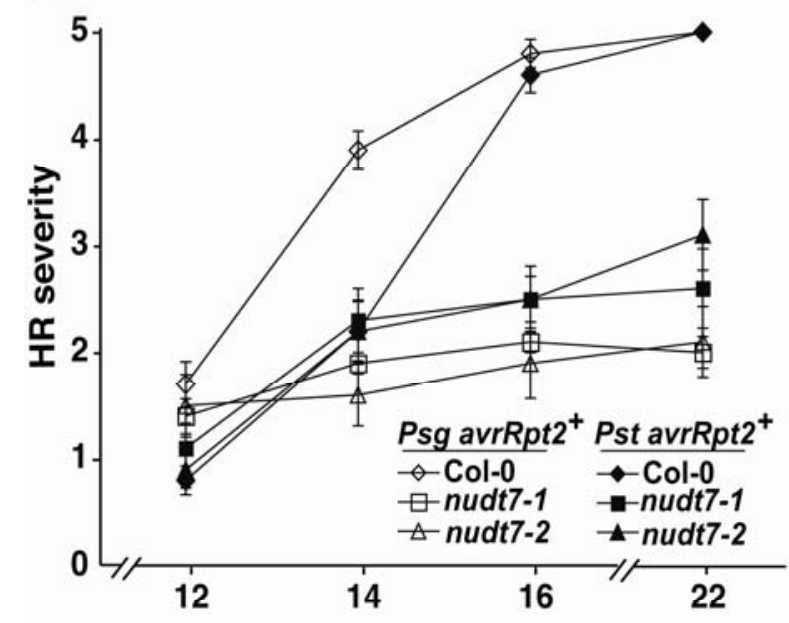

Time After Inoculation (h)
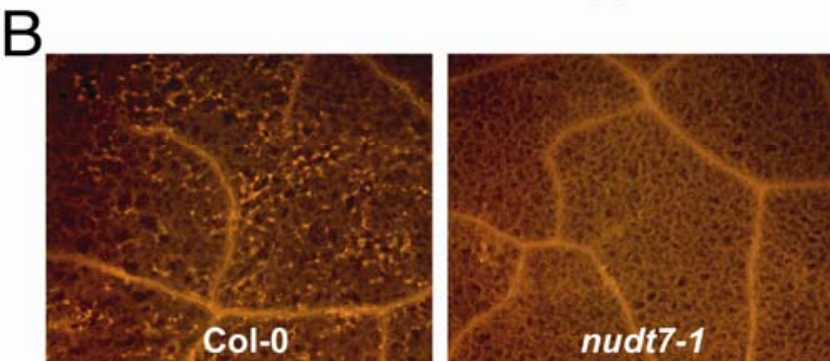

Fig. 4. The $n u d t 7^{-}$mutants display a diminished hypersensitive response (HR) in response to avirulent Pseudomonas syringae pv. tomato. A, HRassociated tissue collapse in leaves of Col-0, nudt7-1, and nudt7-2 plants inoculated on one side of the leaf with either $P$. syringae pv. glycinea R4 + avrRpt 2 or $P$. syringae pv. tomato $\mathrm{DC} 3000+$ avrRpt 2 at $5 \times 10^{7}$ $\mathrm{CFU} / \mathrm{ml}$. Approximately 10 leaves per genotype were scored for severity of HR on a scale from 0 (no collapse) to 5 (100\% collapse) over a time course ranging from 12 to $22 \mathrm{~h}$. B, Autofluorescence detection of HR cell death in leaf mesophyll tissue of wild-type Col-0 (left) or nudt7-1 mutant (right) $24 \mathrm{~h}$ after inoculation with P. syringae pv. glycinea $\mathrm{R} 4$ (avrRpt2) at $1 \times 10^{6} \mathrm{CFU} / \mathrm{ml}$.

\begin{tabular}{|c|c|c|c|c|c|c|c|c|c|c|c|c|c|c|c|c|c|c|c|c|c|c|c|c|c|c|}
\hline \multirow[b]{2}{*}{ AGII } & \multirow[b]{2}{*}{ TIGR Gene Annotation } & \multicolumn{5}{|c|}{$\begin{array}{l}\text { DC+avrRpt2/mock } \\
\text { GeneSpring }\end{array}$} & \multicolumn{5}{|c|}{ DC+avrRpm 1/mock } & \multicolumn{5}{|c|}{ DC+avrPphB/mock } & \multicolumn{5}{|c|}{ DC+avrRps4/mock } & \multicolumn{5}{|c|}{ DC (no avr)/mock } \\
\hline & & & & FC & LBFC & $p$ & FC & $p$ & FC & LBFC & $p$ & & Prob & FC & LBFC & $p$ & & $p$ & $F C$ & LBFC & $p$ & & $p$ & FC & $\angle B F C$ & $p$ \\
\hline At4939030 & enhanced disease susceptibility 5 (Eds5) & 5.94 & 0.016 & 5.60 & 4.41 & & 4.15 & 0.015 & 3.69 & 2.48 & & 5.95 & 0.006 & 5.65 & 2.77 & & & & & & & & & 1.92 & & \\
\hline 2904430 & MutT/nudix family protein (NUDTS) & 6.40 & 0.014 & 5.46 & 4.65 & 0.006 & 3.10 & 0.036 & 2.72 & 2.06 & $\begin{array}{ll}6 & 0.018\end{array}$ & 2.81 & 0.034 & 2.98 & 2.04 & 0.0 & 2.36 & 0.058 & & 1.79 & 0.042 & 1.61 & 0.203 & 1.77 & & 50.141 \\
\hline 2905940 & similar to auxin-regulated dual specificity cytosolic kinase & 3.31 & 0.022 & 3.64 & 3.10 & 0.004 & 2.62 & 0.033 & 2.69 & 2.35 & $\begin{array}{lll}5 & 0.009\end{array}$ & 2.42 & 0.061 & 3.02 & 1.80 & 0.012 & 2.19 & 0.052 & 2.30 & 1.52 & 0.016 & 1.85 & 0.105 & 2.11 & 1.33 & 30.059 \\
\hline At4904500 & receptor-related protein kinase & 3.92 & 0.023 & 2.93 & 2.03 & $3 E-05$ & 2.81 & 0.031 & 2.45 & 1.64 & $4 \quad 6 E-05$ & 3.83 & 0.016 & 2.83 & 1.61 & $6 E-05$ & 2.54 & 0.045 & 2.13 & 1.43 & $2 E-04$ & 2.09 & 0.072 & 1.82 & 1.15 & $\begin{array}{lll}5 & 1 E-04 \\
-15\end{array}$ \\
\hline 3952430 & phytoalexin-deficient 4 protein (pad4) & 4.18 & 0.028 & 3.13 & 2.60 & $2 E-05$ & 2.72 & 0.051 & 2.06 & 1.72 & $2 \quad 2 E-04$ & 3.19 & 0.038 & 2.20 & 1.87 & $9 E-05$ & 2.36 & 0.076 & 1.81 & 1.52 & $3 E \cdot 04$ & 1.74 & 0.200 & 1.41 & 1.07 & 70.002 \\
\hline & givcosy & 2.63 & 0.053 & 2.52 & 2.12 & $2 E-05$ & 2.87 & 0.049 & 2.54 & 2.13 & $\begin{array}{lll}3 & 2 E-05\end{array}$ & 2.75 & 0.051 & 2.43 & 2.10 & $2 \mathrm{E}-05$ & 2.39 & 0.076 & 2.19 & 1.86 & $4 E-05$ & .51 & 0.338 & 1.49 & 1.29 & \\
\hline & cy & 10.48 & 0.013 & 6.27 & 4.30 & $4 E-04$ & 9.40 & 0.016 & 6.15 & 4.49 & $94 \mathrm{E}-04$ & 5.88 & & 4.16 & 3.07 & & 2.18 & 0.157 & 1.54 & 1.03 & 0.017 & 87 & 0.305 & 1.66 & $\begin{array}{ll}5 & 1.08\end{array}$ & $\begin{array}{lll}8 & 0.052\end{array}$ \\
\hline & & & & 2.90 & 2.42 & & 3.05 & & 3.03 & 2.33 & & 2.46 & & 2.65 & 1.98 & & 1.76 & 0.098 & 1.67 & 1.10 & 0.205 & 72 & & 1.67 & 1.06 & $\left.\begin{array}{ll}6 & 0.131\end{array}\right]$ \\
\hline & & 3.55 & 0. & 3.07 & 2.32 & 0.00 & 3.09 & 0. & 2.72 & 2.20 & & 2.63 & 0 & 2.50 & 1.68 & 3 & 1.79 & 0.128 & 1.63 & 1.19 & 0.03 & 70 & 31 & 1.64 & 37 & 70.047 \\
\hline & & 3.98 & 0.009 & 2.67 & 2.02 & $2 E-$ & 4.26 & 0.0 & 2.93 & 2.55 & 51 & 3.28 & 0.015 & 2.18 & 1.67 & 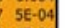 & 1.65 & 0.133 & 1.27 & 1.08 & 0.011 & .70 & 0.128 & 1.33 & 1.04 & $\begin{array}{lll}4 & 0.012\end{array}$ \\
\hline 902920 & givtath & 2.78 & 0.029 & 2.34 & 1.98 & $1 \mathrm{E}-04$ & 2.41 & 0.036 & 2.15 & 1.88 & $8 \quad 2 E-04$ & 2.29 & 0.040 & 2.06 & 1.56 & 4 E- & 1.31 & 0.332 & 1.29 & 1.04 & 0.028 & .43 & 0.270 & 1.37 & 1.04 & $\begin{array}{ll}4 & 0.032\end{array}$ \\
\hline & heat sh & 3.15 & 0.026 & 2.97 & 2.59 & 0.003 & 2.51 & 0.039 & 2.35 & 2.03 & & 2.56 & 0.032 & 2.41 & 1.50 & 0.0 & 1.79 & 0.107 & 1.70 & 1.32 & 0.021 & .90 & 0.120 & 1.89 & 1.17 & 70.029 \\
\hline 5 & poly & 3.06 & 0.035 & 3.53 & 2.95 & 0.002 & 2.74 & 0.047 & 2.34 & 1.91 & 10.003 & 2.30 & 0.077 & 2.93 & 1.65 & 0.001 & 1.83 & 0.148 & 1.98 & 1.58 & 0.007 & 2.01 & 0.111 & 2.04 & 1.71 & $\left.\begin{array}{ll}1 & 0.021\end{array}\right]$ \\
\hline 20 & light re & 2.59 & 0.009 & 3.03 & 2.23 & 0.006 & 1.97 & 0.022 & 2.48 & 1.91 & 10.006 & 1.62 & 0.058 & 2.21 & 1.62 & 0.031 & 1.02 & 0.918 & 1.42 & 1.08 & 0.034 & 1.39 & 0.205 & 1.92 & 1.17 & $\begin{array}{ll}7 & 0.014 \\
\end{array}$ \\
\hline & glucose $-6 \cdot \mathrm{p}$ & 3.21 & 0.041 & 3.48 & 2.10 & 0.0 & 3.23 & 0.035 & 3.06 & 1.86 & $\begin{array}{ll}6 & 0.00\end{array}$ & 3.03 & 0.040 & 2.69 & 1.46 & $\begin{array}{ll}5 & 0.01\end{array}$ & 1.41 & 0.330 & 1.33 & 0.80 & 0.374 & 1.71 & 0.176 & 2.09 & 1.17 & $\begin{array}{ll}7 & 0.04\end{array}$ \\
\hline & myb f: & 3.01 & 0.027 & 4.41 & 2.94 & $2 E-$ & 2.16 & 0.055 & 3.40 & 2.35 & $58 \mathrm{E}-06$ & 2.76 & 0.030 & 4.85 & 3.22 & $29 E-07$ & 1.42 & 0.269 & 2.49 & 1.64 & $4 E-06$ & 1.25 & 0.502 & 2.13 & 1.42 & $\begin{array}{lll}2 & 2 \mathrm{E}-04\end{array}$ \\
\hline & Mut & 3.32 & & 2.50 & 1.99 & 0.0 & 2.29 & & 1.89 & 1.70 & & 2.86 & & 2.39 & 1.95 & & 2.03 & & 1.68 & 1.34 & 0.01 & .61 & & 1.39 & 19 & \\
\hline & & & & 2.93 & 1.97 & & 15 & & 2.65 & 2.00 & $\begin{array}{ll}0 & 0.013\end{array}$ & 71 & & 2.80 & 1.91 & & 1.77 & & 2.03 & 46 & 0.0 & & & 87 & & \\
\hline & & & & 2.49 & 1.96 & 1 & 2.31 & & 2.00 & 1.59 & & 42 & & 2.87 & 1.83 & & 2.07 & & 1.83 & 1.08 & 0.005 & 47 & & 1.38 & 08 & \\
\hline & & & 0.021 & 2.81 & 2.32 & $1 \mathrm{E}-04$ & 2.64 & 0. & 2.42 & 1.69 & & 2.55 & & 2.57 & 1.75 & & 1.87 & & 1.87 & 1.38 & $5 E-04$ & 43 & & 1.59 & 1.04 & $\begin{array}{lll}4 & 6 \mathrm{E}-04\end{array}$ \\
\hline & & & & 2.39 & 2.00 & SE. 0 & 2.42 & & 1.99 & 1.66 & & 2.62 & & 2.33 & 1.73 & $8 E-04$ & & & 1.18 & 0.93 & 0.084 & & & 45 & & $\begin{array}{ll}4 & 0.021\end{array}$ \\
\hline & & & 0 & 2.45 & 1. & & 2.98 & & 2. & 1.72 & & 0 & & 2. & 1.6 & 0.0 & & 0 & 1. & 1.22 & 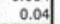 & 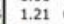 & & 1.30 & 6 & $\begin{array}{ll}60 & 0 .\end{array}$ \\
\hline & & & 0.8 & 4.50 & 2.79 & 0.00 & 2.34 & 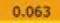 & 2.52 & 1.92 & & 2.76 & 0.04 & 3.15 & 1.4 & 7 & 1 & & 2. & 1.39 & 0.015 & 76 & & 1.72 & 3 & 30067 \\
\hline & & & 0. & 3.94 & 2.51 & & 2 & 0. & 2.51 & 1.64 & & 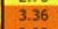 & & 3.32 & 1.87 & & 1. & 0. & 1. & 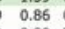 & & 2 & 0.450 & 1.31 & & 0.3 \\
\hline & & 4.35 & 0. & 2.13 & 1.52 & $1 \mathrm{E}$ & 4. & 0. & 2.37 & 2.02 & 28 & 93 & & 2.33 & 2.01 & 1.2 & 1. & 0. & 1.10 & 0.89 & & 39 & & .04 & 7 & $\begin{array}{ll}7 & 0.003\end{array}$ \\
\hline & IGP & & 0 . & 2.12 & 1.78 & 0.002 & 7 & 0.8 & 2.12 & 1.97 & & 12 & & 2.16 & 1.73 & & & & 1.38 & 1.27 & 0.009 & 56 & & 1.52 & 1.10 & $\begin{array}{ll}0 & 0.031\end{array}$ \\
\hline & e ARK3 & & 0.0 & 2.26 & & & & & 2.42 & 1.84 & & 2.58 & & 2.27 & 1.52 & & & & 1.68 & 1.38 & 1E-04 & 56 & 0.201 & 1.58 & 1.25 & $\begin{array}{ll}5 & 0.002\end{array}$ \\
\hline & & & & 2.40 & & 0.016 & 2.31 & 0.0 & 2.33 & 1.65 & & 2.28 & & 2.37 & 1.72 & & & & 1.70 & 1.28 & 0.045 & 56 & 0.161 & 1.69 & 1.28 & $\begin{array}{ll}8 & 0.182\end{array}$ \\
\hline & sp & & 0.031 & 2.09 & 1.75 & $2 \mathrm{E}$ & 2.49 & 0.03 & 1.80 & 1.54 & $4 \quad 6 E-04$ & 2.53 & 0.031 & 1.98 & 1.48 & 30.001 & 2.01 & 0.060 & 1.62 & 1.31 & $8 E-04$ & .64 & 0.144 & 1.42 & 1.20 & {$\left[\begin{array}{ll}0 & 0.011\end{array}\right]$} \\
\hline & disease & 2.31 & 0.032 & 1.84 & 1.57 & 0.00 & 2.18 & 0.037 & 1.83 & 1.52 & $\begin{array}{ll}2 & 0.01\end{array}$ & 2.02 & & 1.88 & 1.30 & 0.0 & 1.73 & 0. & 1.47 & 1.28 & 0.037 & 1.61 & 0.131 & 1.34 & 1.06 & $\left.\begin{array}{ll}6 & 0.083\end{array}\right]$ \\
\hline & & 2. & 0.0 & 2.44 & 1.54 & & 2.05 & 0.075 & 2.04 & 1.68 & $\begin{array}{ll}8 & 0.032\end{array}$ & 3.69 & & 3.42 & 2.30 & 0.01 & 1.95 & 0.144 & 2.01 & 0.83 & 0.045 & 1.43 & 0.371 & 1.50 & 0.73 & $\begin{array}{ll}30 & 0 .\end{array}$ \\
\hline & & & 00 & 2.36 & 1.53 & & 2.50 & & & 165 & & 2.68 & & & 140 & & & & & & & & & 1.54 & & \\
\hline & & & & 2. & 1.55 & & I. & & & & & & & 2. & 1. & & & & & & & & & & & \\
\hline & & & 0. & 2. & 1.45 & & 2 & & & 1.63 & & & & 2. & 1. & & & & & & & & & & & \\
\hline & & & & 1. & & & 4. & & 1. & & & & & 1. & & & & & & & & & & & & \\
\hline & & 3. & 0.0 & 2.5 & 1.32 & & 2.72 & & 2. & 1.30 & & & & & & & & & & & & & & & & \\
\hline & & 2. & 0.0 & 1.68 & 1.37 & 0.0 & 2.21 & 0.0 & 1.58 & 1.35 & 50.0 & 2.38 & & 1.82 & 1.39 & 0 & 1. & 0.0 & 1.27 & 1.0 & & ( & 0.136 & 1.32 & 1.06 & $\left.\begin{array}{ll}6 & 0.083\end{array}\right]$ \\
\hline & & & 0.040 & 1.74 & 1.29 & & 1.93 & 0.044 & 1.77 & 1.30 & & 1.89 & 0.046 & 1.70 & 1.28 & & 31 & 0.271 & 1.27 & 0.96 & & 1.63 & 0.093 & 1.38 & 1.03 & $\begin{array}{lll}3 & 0.347\end{array}$ \\
\hline
\end{tabular}

Fig. 3. The 38 genes that exhibited reliable transcript abundance changes for three or more resistance-avirulence ( $R-a v r)$ treatments, relative to mock-inoculated plants, in DC3000 experiments. Color intensities represent strength of conclusion that the transcript was more (orange) or less (blue) abundant in treatment than in the control, as described in the color key in Figure 2. FC = fold-change in transcript abundance, $\mathrm{P}=$ probability, and LBFC $=$ lower bound of fold-change confidence interval. 
A

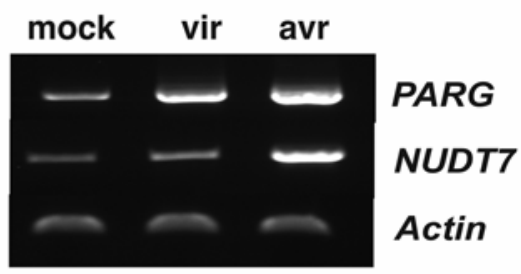

B

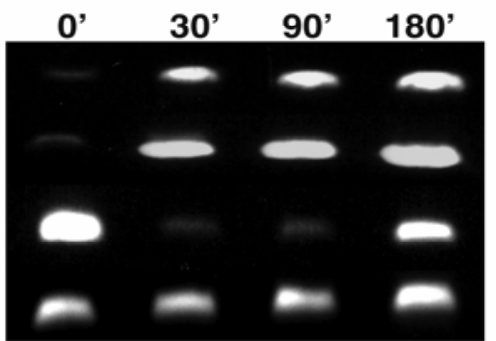

PARG

NUDT7

TIR1

Actin

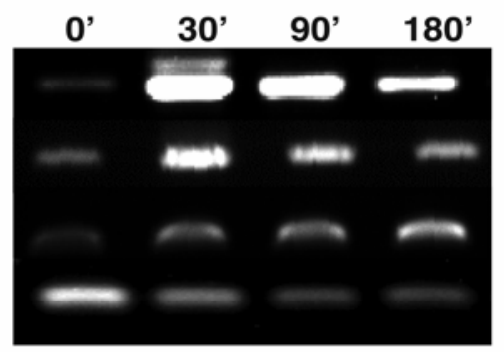

PARG

NUDT7

WRKY29

Actin
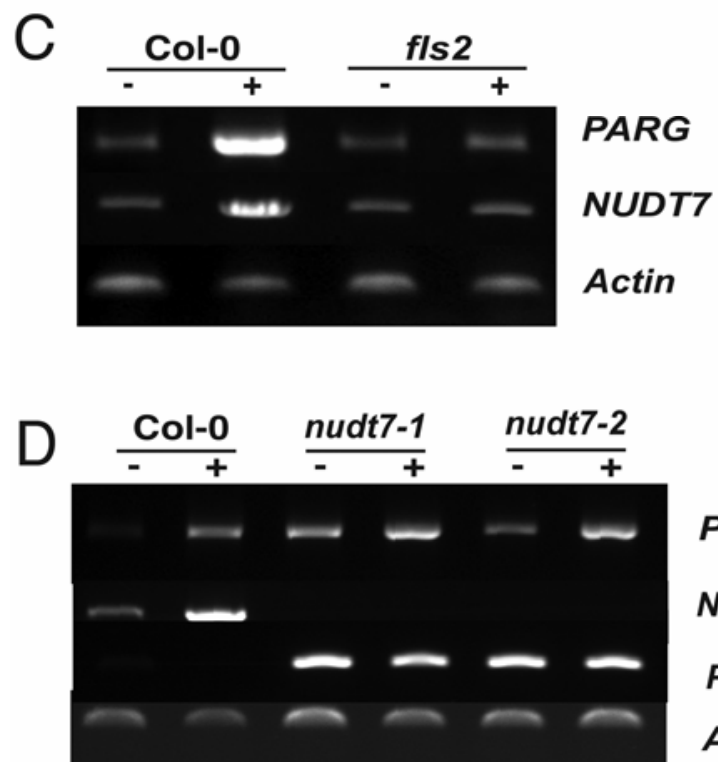

PARG

NUDT7

PR-1

Actin

Fig. 5. NUDT7 and poly(ADP-ribose) glycohydrolase (PARG) gene expression is upregulated upon treatment with flg22 and is dependent upon functional FLS2. Semiquantitative reverse-transcription polymerase chain reaction was performed on RNA extracted from A, 5-week-old Arabidopsis vacuum infiltrated with $10 \mathrm{mM} \mathrm{MgCl}{ }_{2}$ (mock) or with Pseudomonas syringae pv. tomato DC3000 (virulent) or P. syringae pv. tomato DC3000 + avrRpt2 (avirulent) at $1 \times 10^{5} \mathrm{CFU} / \mathrm{ml}$ or B, 2-week-old Arabidopsis seedlings treated with $10 \mu \mathrm{M}$ flg22 peptide over a time course ranging from 0 (water-treated control) to $180 \mathrm{~min}$. Two independent biological experiments are shown. TIRI gene expression is negatively regulated by flagellin treatment (Navarro et al. 2006) while WRKY29 gene expression serves as a positive control (Asai et al. 2002). C, Wild-type or fls2 mutant seedlings treated with (+) or without (-) $10 \mu \mathrm{M}$ flg22 for $2 \mathrm{~h}$. D, Wild-type or $n u d t 7$ mutant seedlings treated with (+) or without (-) $2.5 \mu \mathrm{M}$ flg 22 for $2 \mathrm{~h}$. however, the four genes for which an altered plant response to pathogens was observed are targets for future study.

Poly(ADP-ribosyl)ation-related gene expression and plant defense responses.

Two plant lines carrying independent nudt7 SALK T-DNA mutant alleles identified from the knockout study exhibited elevated resistance to virulent DC3000 (data not shown). Similar results with Arabidopsis nudt7 mutants and virulent pathogens subsequently were published by three other groups (Bartsch et al. 2006; Ge et al. 2007; Jambunathan and Mahalingam 2006). We observed an additional defense-associated phenotype: a diminished HR (Fig. 4). Leaves initially were tested with high titers of avirulent $P$. syringae expressing avrRpt2 to monitor macroscopically visible collapse (Fig. 4A) and the reduced HR then was confirmed using autofluorescence microscopy to track death of individual mesophyll cells in response to lower, more biologically realistic inoculum titers (Fig. 4B). In multiple independent experiments, HR cell death was not entirely absent but was greatly attenuated relative to wild-type Arabidopsis Col-0. In addition, an increased sensitivity to inoculation damage was noted for the nudt7 mutants in multiple experiments in which a plastic syringe with no needle was used to gently introduce pathogen suspensions into leaf mesophyll tissue.

NUDT7 has been shown to exhibit ADP-ribose pyrophosphatase activity in vitro (Jambunathan and Mahalingam 2006; Ogawa et al. 2005; Olejnik and Kraszewska 2005). ADPribose pyrophosphatase converts ADP-ribose into AMP and ribose 5-phosphate, thus limiting pools of reactive (and hence toxic) free ADP-ribose (Ogawa et al. 2005). Poly(ADP-ribose) glycohydrolase (PARG) is one of the major enzymes responsible for generating free ADP-ribose in response to the activation of poly(ADP-ribosyl)ation (discussed below). Strikingly, we discovered that At2g31865 (PARG) is one of the few other genes whose transcript levels reliably increased upon infection with avirulent $P$. syringae pv. tomato during multiple $R$-avr interactions (Fig. 3, confirmed in Fig. 5A).

The expression of NUDT7 and PARG genes during plant innate immune responses also was examined. The flagellinbased peptide flg22 is a potent elicitor of plant basal defenses (Felix et al. 1999; Gomez-Gomez et al. 1999). Expression of NUDT7 and At2g31865/PARG mRNA is upregulated upon flg22 treatment (Fig. 5B). This upregulation by flg22 treatment was dependent upon the presence of the flagellin receptor FLS2, because neither transcript accumulated in fls2 mutant seedlings treated with flg22 (Fig. 5C).

In nudt 7 mutants, $P A R G$ gene expression was constitutively elevated (Fig. 5D). Note that pathogenesis-related (PR)-1 expression also was elevated in untreated asceptically grown nudt7 mutants from the same experiment (Fig. 5D). Mutant nudt 7 plants still exhibited flg22 responses (seedling growth inhibition and callose deposition) (Supplemental Fig. S4).

\section{Inhibition of poly(ADP-ribose) polymerase also} alters defense responses.

The above results suggested further examination of poly(ADP-ribosyl)ation processes during plant defense responses. Poly(ADP-ribosyl)ation is a post-translational protein modification that is known to influence human ischemia, inflammation, plant light stress, and other cellular stresses (Burkle 2005; Gagne et al. 2006; Hunt et al. 2004). Protein poly(ADP-ribosyl)ation is carried out by poly(ADP-ribose) polymerases (PARPs) (note that the glycohydrolase activity of PARG counters PARP by removing these poly(ADP-ribose) polymers). Mutational analysis of PARPs is difficult because Arabidopsis, humans, and other eukaryotes carry multiple 
PARP genes; however, commercially available inhibitors such as 3-aminobenzamide (3-AB) often are used to disrupt PARP activity (Jagtap and Szabo 2005). These inhibitors have been shown to be specific in their ability to inhibit PARP activity and not other NAD ${ }^{+}$-consuming enzymes (Banasik et al. 1992; Hunting et al. 1985; Purnell and Whish 1980; Rankin et al. 1989), and have been used successfully in Arabidopsis and other plants (Berglund et al. 1996; De Block et al. 2005; Panda et al. 2002). We observed that PARP inhibition by 3-AB blocked flg22-induced callose deposition in Arabidopsis seedlings (Fig. 6A). Treatment with a separate defense elicitor, the bacterial EF-Tu-derived peptide elf18, also elicits callose deposition (Zipfel et al. 2006). As for flg22, callose deposition in response to elf 18 was blocked by treatment with $3-\mathrm{AB}$ (Fig. $6 \mathrm{~A})$.

In addition, PARP inhibition converted one or more FLS2mediated responses into an overtly toxic response (Fig. 6B). Seedling growth inhibition is common in plants that have continuously activated defenses and is a widely used assay for plant innate immune responses such as FLS2 activation by flagellin or flg22 (Chinchilla et al. 2007; Dunning et al. 2007; Felix et al. 1999; Gomez-Gomez and Boller 2000; Sun et al. 2006). However, flg22 elicited dramatic and much more severe seedling growth inhibition in the presence of PARP inhibitor, and did so only if the plants carried a functional FLS2 (Fig. 6B and $\mathrm{C}$ ). In the absence of flg22, 3-AB-treated seedlings did not grow as well as untreated seedlings (Fig. 6C) but growth in 3$\mathrm{AB}+$ flg22 was highly toxic (Fig. $6 \mathrm{~B}$ and $\mathrm{C}$ ). The loss of flg22-induced callose deposition in the presence of $3-\mathrm{AB}$, together with the FLS2-dependent toxicity of multiday growth in $3-\mathrm{AB}+$ flg22, suggests that FLS2-mediated responses are partially disrupted and unfavorably diverted by inhibition of poly(ADP-ribosyl)ation.

The toxicity that PARP inhibition causes during FLS2-mediated responses apparently does not act through NPR1, salicylate, or NDR1-mediated pathways, because Arabidopsis npr12, pad4-1, (Glazebrook et al. 1996), and ndrl-1 (Century et al. 1995) mutations did not relieve this response (Fig. 6D). However, ein2-1 mutants (Guzman and Ecker 1990) displayed wild-type responsiveness to flg22 alone but displayed significantly less seedling toxicity than wild-type plants in the presence of 3-AB + flg22 (Fig. 6D). This suggests that ethylene responses are partially responsible for the toxicity that FLS2mediated responses cause when PARP has been inhibited. Isoxaben-resistant Arabidopsis ixr mutants (Desprez et al. 2002; Scheible et al. 2001) also were tested, because these cellulose synthase mutants resist isoxaben-induced callose and lignin deposition. Intriguingly, the ixr mutants were noticeably more sensitive than the wild type to the toxicity of FLS2-mediated responses in the presence of PARP inhibition (Fig. 6E), even after data normalization to account for the smaller size of untreated $i x r$ mutants, suggesting a linkage between poly(ADPribosyl)ation and the regulation of cell wall modification during plant defense responses.

\section{DISCUSSION}

A single host genotype and isogenic $P$. syringae strains were used to compare the Arabidopsis transcript profiles induced by four different $R$-avr pairings. Multiple significance criteria were utilized to reduce false-positive inclusion of genes that were not reliably regulated by a given $R$-avr interaction. The identified genes can serve as targets for future signal transduction studies, promoter dissection, gene knockout work, or other studies. In the present study, an apparent role for poly(ADP-ribosyl)ation in plant-pathogen interactions was revealed.
Data analysis challenges in expression profiling studies.

We found that different data analysis packages identified quite different sets of genes from the same initial experimental data (Fig. 1). Some of the differences may have arisen because the data set contained two rather than three biological replicates of each treatment, three being more commonly preferred. However, the poor agreement between different expression profile data analysis methods has been examined in the bioinformatics literature (Abruzzo et al. 2005; Jeffery et al. 2006; Millenaar et al. 2006; Nadon and Shoemaker 2002; Shedden et al. 2005; Slonim 2002; Smyth et al. 2003; Stafford and Brun 2007). Multiple statistical tests have been recommended to generate a more refined list of differentially expressed genes (Abruzzo et al. 2005; Kannangara et al. 2007; Millenaar et al. 2006). We did this using commonly accepted analysis methods: GeneSpring $P$ value, dChip lower bound of confidence interval for fold-change, and ANOVA. These analysis methods use not only different statistical models but also different forms of input data derived from the same original raw data.

\section{Differentiation among $\boldsymbol{R}$-avr interactions.}

One goal of the present study was to identify genes that were robust indicators of a given $R$ - $a v r$ interaction. The time point $14 \mathrm{~h}$ after inoculation was chosen for sampling based on prior published studies of Arabidopsis responses to $P$. syringae. Occurring well after initial plant responses to handling, after the pathogen has adapted to the plant interior and initiated type III secretion-mediated suppression of defenses (approximately 2 to $3 \mathrm{~h}$ after inoculation), and after the earliest $R$ gene-mediated defense signaling events have occurred, the 14$\mathrm{h}$ time point represents a time at which plant defense responses are well underway. However, it also is known that plant responses to different $R$-avr interactions can arise at different rates and with different intensities (as measured, for example, by PR-1 gene induction or strength of restriction of pathogen growth). Macroscopic differences in the plant response as well as different levels of economic disease control have been observed historically with many different $R$ - $a v r$ gene pairings (McDowell et al. 2000; McIntosh et al. 1995; Minsavage et al. 1990). Specific to the present experiments, RPM1-avrRpm1 responses frequently have been reported to arise more rapidly than RPS2-avrRpt 2 responses and both of these responses are stronger than the response of ecotype Col- 0 mediated by RPS4-avrRps4 (Ritter and Dangl 1996; Yu et al. 1998). Hence, it is not surprising that substantial differences were observed in the expression profiles for the different $R$ - $a v r$ interactions. After this study and other expression profiling studies, it remains difficult to identify canonical genes whose expression distinguishes particular $R$ - $a v r$ interactions. However, the data from the present study emphasize that, even when isogenic host and pathogen strains are used in a controlled environment, the plant responses mediated by different $R$-avr interactions can differ dramatically.

\section{Overlap in responses to virulent and avirulent pathogen.}

A much smaller number of transcripts showed significant abundance change during $R$ - $a v r$ interactions when the compatible interaction with DC3000 (no avr) was used as the baseline or control rather than using mock-inoculated plants as the control. Many of the transcripts elevated during the $R$-avr interaction also were elevated, but to a lesser extent, in response to DC3000 with no $a v r$, as has been reported previously (Tao et al. 2003). This corroborates previous observations that virulent and avirulent strains of a pathogen often induce similar PR genes and other defense-associated responses, but the responses occur more rapidly or more strongly at early timepoints in reaction to avirulent strains than they do to virulent 
A
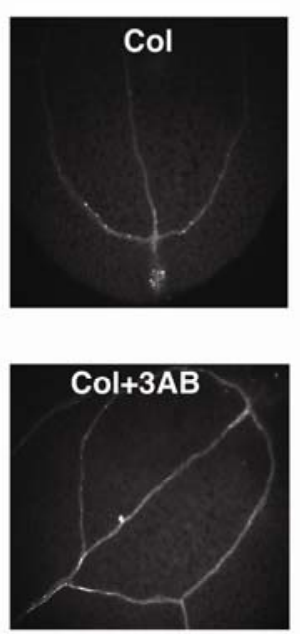
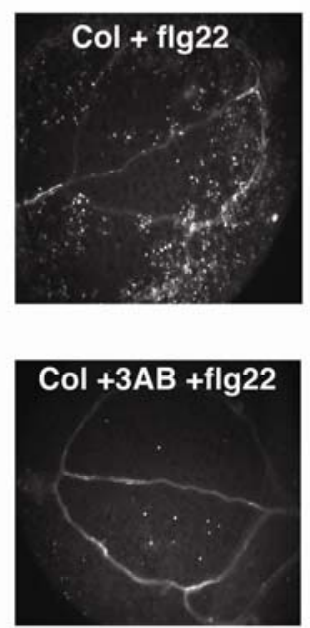

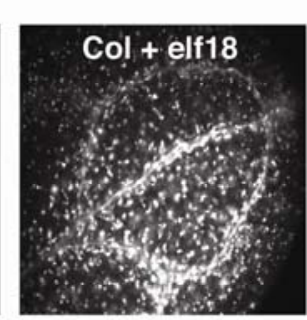

Col +3AB + elf18

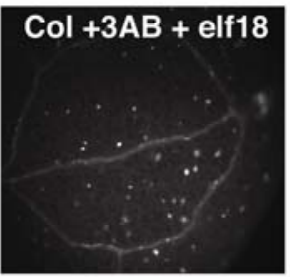

B

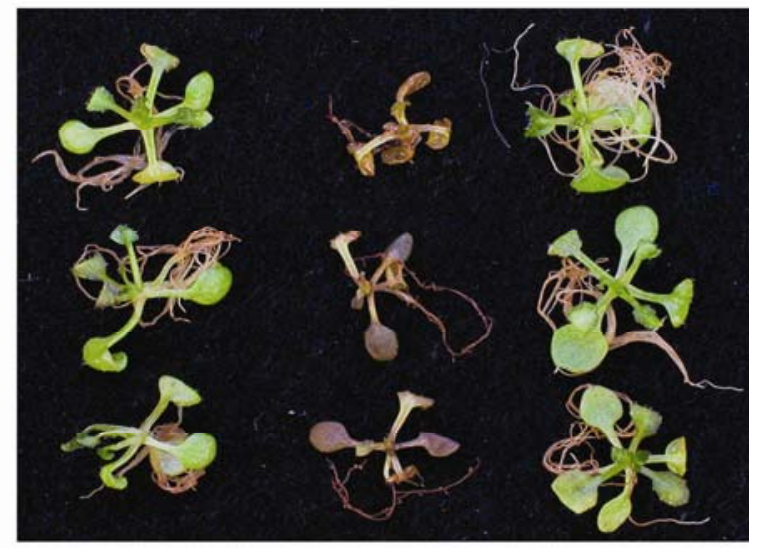

C

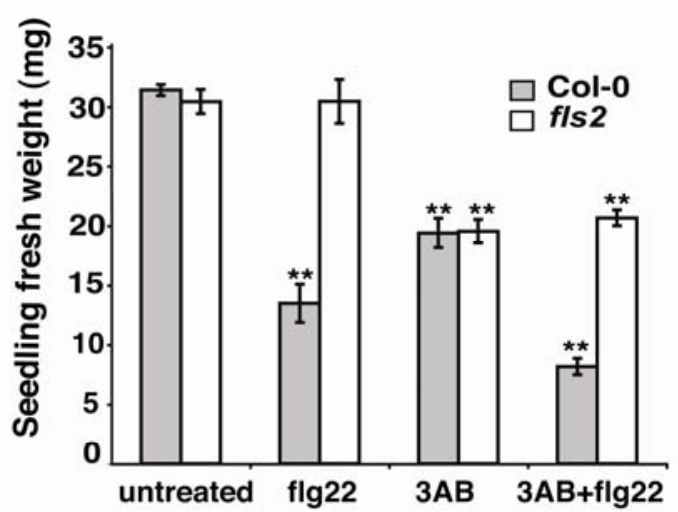

D

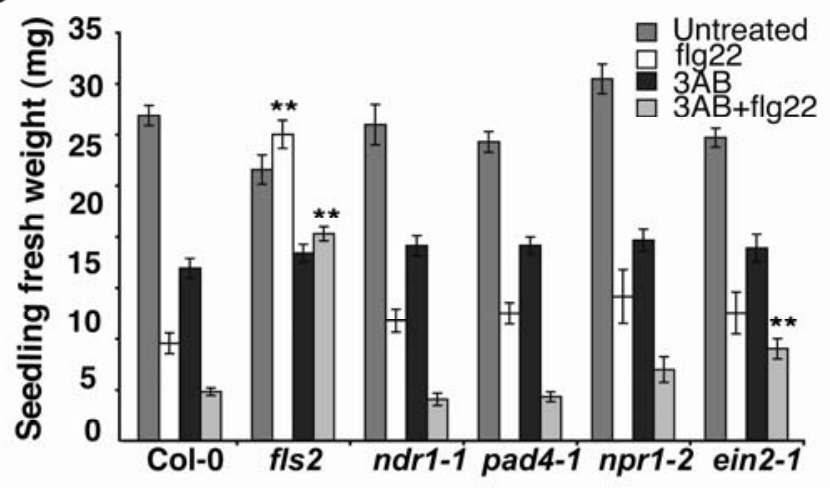

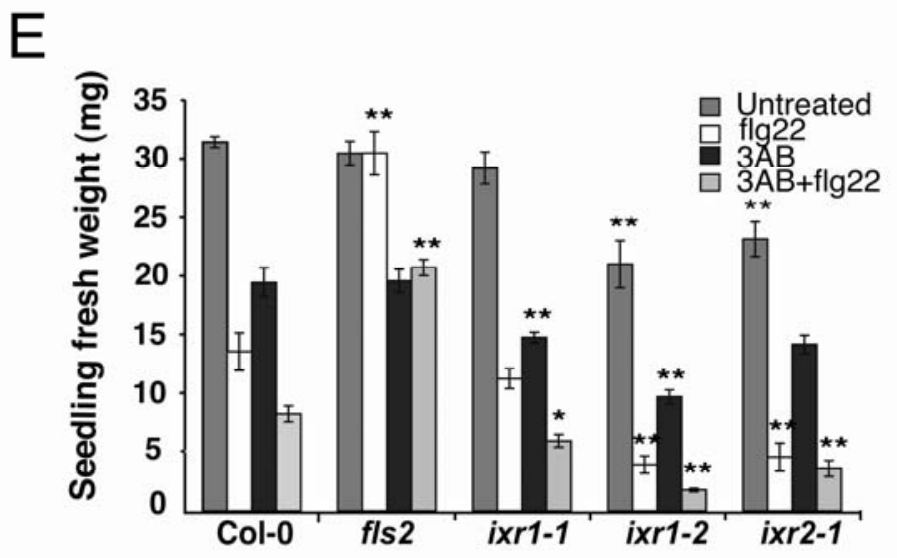

Fig. 6. Inhibitors of poly(ADP-ribosyl)ation impact plant basal defense responses to flg22. A, Ten-day-old Arabidopsis seedlings treated with $0.6 \%$ dimethyl sulfoxide (DMSO) with or without $5 \mathrm{mM} 3$-aminobenzamide (3-AB) for $24 \mathrm{~h}$. Seedlings then were treated with $2.5 \mu \mathrm{M}$ either flg22, elf 18 , or water for $24 \mathrm{~h}$, fixed with aniline blue, and examined for autofluorescent callose staining. B, Wild-type or fls 2 seedlings were grown in liquid Murashige-Skoog (MS)/sucrose for 10 days, at which time 3-AB was added to the growth medium (to a final concentration of $5 \mathrm{mM}$ ), followed $2 \mathrm{~h}$ later by addition of flg22 (to a final concentration of $10 \mu \mathrm{M}$ ) or water. Pictures were taken after 10 additional days of growth. C, Wild-type or fls 2 seedlings were grown in liquid MS/sucrose for 10 days, at which time $0.6 \%$ DMSO with or without 3-AB was added to the growth medium (to a final concentration of 2.5 mM), followed $24 \mathrm{~h}$ later by addition of flg22 (to a final concentration of $10 \mu \mathrm{M}$ ) or water. Seedling weight was recorded after 10 days of additional growth in this solution. The experiment was repeated on four separate dates; asterisks summarize results across these four dates for analysis of variance (ANOVA) tests of similarity of means between the treatment and untreated control plant of the same genotype (Tukey's simultaneous test; $* *=P<0.001 ;$ no asterisk $=P>0.05$ ). $\mathbf{D}$ and E, Experiments performed as described for $\mathrm{C}$ using the designated Arabidopsis Col-0 mutant plant lines. Asterisks summarize ANOVA results across three separate experiments (exception: for the 3-AB-only treatment, experiments with $n d r 1-1$ and nprl-2 were done twice). To account for differences in growth of untreated seedlings of the different genotypes, graphs show actual seedling weight data for one experiment; however, ANOVA tests used, as input data, the weight for each seedling normalized to the within-experiment average weight of the untreated controls of the same genotype. ANOVA tests were for similarity of means between each genotype and the wild-type control subjected to the same flg 22 or 3 -AB treatment (Tukey's simultaneous test; $*$ and $* *=P<$ 0.05 and 0.001 , respectively; no asterisk $=P>0.05$ ). 
strains (Lucas 1998). Experiments performed using $P$. syringae pv. glycinea R4 identified only a small set of significantly regulated genes, nearly all of which also were identified in the DC3000 experiments. Note again that DC3000 (lacking an $a v r$ transgene) is virulent on Arabidopsis ecotype Col-0 whereas R4 (lacking an $a v r$ transgene) is not virulent on this host. In the present study, we were left with the impression that $\mathrm{R} 4$ is less effective at delivering $R$-activating $a v r$ signals, possibly as a quantitative rather than a clearly qualitative difference.

\section{ADP-ribosylation and defense responses.}

Follow-up study of 20 candidate genes identified from the expression profiling experiments revealed an association between ADP-ribosylation and defense responses. NUDT7 is one of at least four Arabidopsis nudix hydrolases with ADP-ribose pyrophosphatase activity (Jambunathan and Mahalingam 2006; Ogawa et al. 2005; Olejnik and Kraszewska 2005). NUDT5 also was upregulated in our study (Fig. 3); however, its product apparently does not exhibit ADP-ribose pyrophosphatase activity (Ogawa et al. 2005). When nudt5 knockout lines were tested, we did not detect defense alteration. In addition to the upregulated expression of NUDT7 that we observed in three $R$-avr interactions (Fig. 3), other studies have noted elevated NUDT7 gene expression in response to flg22 treatment (Navarro et al. 2004), and PAD4- and EDS1-dependent regulation in response to $P$. syringae expressing avrRPS4 (Bartsch et al. 2006). A leading hypothesis is that NUDT7 contributes to the removal of toxic ADP-ribose (Bartsch et al. 2006; Ogawa et al. 2005). Several studies in addition to this study have now identified increased restriction of virulent pathogen growth in nudt7 mutants (Bartsch et al. 2006; Ge et al. 2007; Jambunathan and Mahalingam 2006).

We observed two additional phenotypes not reported in other nudt7 studies: a significant reduction in the growth of avirulent $P$. syringae pv. tomato in nudt7 mutants and a clear and reproducible loss of HR in $n u d t 7$ mutants (Fig. 4). Our observation of a reduced HR in $n u d t 7$ mutants contrasts with a report of a normal HR phenotype for $n u d t 7$ mutants (Ge et al. 2007. The plants used by Ge and colleagues for HR tests were grown in near-aseptic conditions to avoid plant growth phenotypes and constitutive activation of PR gene expression, whereas the plants utilized in our HR study were grown in communal growth rooms and exhibited reduced plant size and constitutive PR-1 gene expression relative to wild-type plants. In our work, there was some variability in the extent of HR reduction across multiple experiments but, in each instance, the HR produced by the nudt7 mutants was significantly attenuated relative to the wild type. This interesting association between constitutive PR expression and reduction of HR cell death also has been observed with other genotypes (for example, with Arabidopsis dnd mutants); however, the correlation is not absolute because other constitutive PR mutants do not exhibit a loss of HR (Yu et al. 1998).

A gene encoding a second component of the poly(ADPribosyl)ation process, $P A R G$, also was identified as being reliably upregulated by three or more $R-a v r$ interactions and in response to flg22 treatment (Figs. 3 and 5). Only one $P A R G$ gene exists in mammals and insects, whereas there are two apparent PARG genes located in tandem on Arabidopsis chromosome 2 (At2g31865, identified in this study, and At $2 \mathrm{~g}$ 31870). A third PARG gene may exist (At2g31860); however, it does not have any expressed sequence tags (EST) or cDNAs associated with it and, therefore, may not be expressed (Hunt et al. 2004). The Arabidopsis tej mutation was identified as a lesion in At2g31870 and the protein encoded by the wild-type gene appears to be a regulator of the circadian oscillator in
Arabidopsis (Panda et al. 2002). Very little is known about At2g31865, the $R$-avr-induced $P A R G$ gene. At2g31865 does not have a probe set on the more recent 22,000-gene Affymetrix Arabidopsis chip despite clear EST evidence for the existence of this gene and its transcript and, hence, would remain unnoticed by researchers relying on data from the 22,000-gene chip. PARG is the only known enzyme that can counter the catalytic activity of PARP enzymes. The upregulation of PARG/At2g31865 during defense responses may contribute to recovery efforts in response to pathogen infection. In a separate expression profiling study, $P A R G$ and NUDT7 were among the many genes upregulated in response to $P$. syringae pv. phaseolicola, a nonhost pathogen, but not by virulent $P$. syringae strains (Tao et al. 2003). Enzymes that impact poly(ADP-ribosyl)ation may be a component of the response that is downregulated by type III-secreted effectors that determine $P$. syringae host range.

Poly(ADP-ribosyl)ation of proteins occurs in response to a variety of cellular processes, including DNA repair and transcription, cell cycle regulation, apoptosis, and regulation of telomere length (Burkle 2005; Gagne et al. 2006; Hunt et al. 2004; Oei et al. 2005; Schreiber et al. 2006; Ziegler 2000). PARPs use $\beta-\mathrm{NAD}^{+}$as a substrate, attaching ADP-ribose residues to specific protein acceptors to form branched chains of ADP-ribose polymers. Hence, PARP activity can directly modify target protein function. This process results in the consumption of significant quantities of $\mathrm{NAD}^{+}$and generates substrate that PARG then can act on to release toxic ADP-ribose. Under excessive DNA damage, PARP-1 becomes overactivated, leading to massive consumption of $\mathrm{NAD}^{+}$and ultimately resulting in necrotic cell death (Burkle 2005; Koh et al. 2004). It may be very relevant that PARP is involved in the cell-death response of cultured soybean cells subjected to oxidative stress by treatment with $\mathrm{H}_{2} \mathrm{O}_{2}$ (Amor et al. 1998). When levels of poly(ADP-ribosyl)ation are decreased via PARP inhibition, plants become less sensitive to drought and high light stress (De Block et al. 2005; Vanderauwera et al. 2007). This particular outcome was attributed mainly to prevention of high $\mathrm{NAD}^{+}$consumption. In Catharanthus roseus tissue culture, increases in phenylalanine ammonia-lyase activity were prevented by addition of an inhibitor of poly(ADP-ribose) polymerase (Berglund et al. 1996). We have located no other inquiries into the role of poly(ADP-ribosyl)ation in plant defense.

Poly(ADP-ribosyl)ation was further implicated in plant defense responses when treatment with $3-\mathrm{AB}$, an extensively characterized PARP inhibitor, altered flg22-induced responses. Treatment of seedlings with PARP inhibitor blocked both flg22- and elf18-induced callose deposition (Fig. 6A) and caused FLS2-mediated flg22 responses to become nonproductive and toxic (Fig. 6B and C). This response arose independent of NPR1, PAD4, and NDRl (Fig. 6D). However, ethylene apparently contributes to the toxic response because ein $2 \mathrm{mu}-$ tants were significantly less damaged than wild-type seedlings (Fig. 6D). The increased sensitivity of $i x r$ (cellulose synthase) mutants to FLS2 signaling under PARP inhibition (Fig. 6E) suggests that poly(ADP-ribosyl)ation may impact the regulation of cell-wall modification during plant defense responses. This may arise due to poly(ADP-ribosyl)ation of specific proteins or, alternatively, via modulation of $\mathrm{NAD}^{+}$pools. $\mathrm{NAD}^{+} / \mathrm{NADH}$ ratios impact the level and type of cell wall matrix biosynthetic activity (Seifert 2004).

Additional points about NUDT7 bear mentioning. First, the NUDT7 product has been shown to preferentially hydrolyze both ADP ribose and NADH substrates in vitro (Jambunathan and Mahalingam 2006; Ogawa et al. 2005; Olejnik and Kraszewska 2005), and it remains possible that the defense 
upregulation of NUDT7 expression or the defense phenotypes of $n u d t 7$ mutants are more related to impacts on NAD ${ }^{+} / \mathrm{NADH}$ pools than to removal of free ADP-ribose. Second, the elevated $P A R G$ expression in $n u d t 7$ mutants may be specifically regulated by pathogen-induced alterations in PARP activity or by changes in ADP-ribose or $\mathrm{NAD}^{+}$pools. Alternatively, $P A R G$ may simply be among a larger number of defense-related genes (including PR-1) that are upregulated in $n u d t 7$ mutants, which also carry elevated levels of salicylic acid (Bartsch et al. 2006; Jambunathan and Mahalingam 2006). Third, Ge and associates (2007) found no constitutive elevation of PR-1 expression in $n u d t 7$ mutants grown in isolation, leading them to conclude that mutation of $n u d t 7$ potentiates plants for a heightened response after exposure to pathogenic and nonpathogenic microorganisms. However, when we grew nudt7 seedlings under sterile conditions, we observed constitutive PR-1 expression (Fig. 5D). Potentiation of defenses and constitutive defense expression may both be present in $n u d t 7$ mutants.

In summary, we utilized isogenic plants and pathogens to identify distinguishing features between the gene expression profiles activated by different $R$ - $a v r$ stimuli. When one of these leads was pursued, we found that two genes involved in ADPribosylation are upregulated during both basal and $R$ - $a v r$-elicited defense responses, and that mutation of NUDT7 and chemical inhibition of PARP activity alter these responses. This suggests that poly(ADP-ribosyl)ation makes a significant contribution to appropriate plant defense responses.

\section{MATERIALS AND METHODS}

\section{Experimental design for expression profiling.}

Within a plant block, six or seven pots containing 12 to 16 plants per pot were grown adjacently in the same flat and then individual pots were either mock inoculated with $10 \mathrm{mM}$ $\mathrm{MgCl}_{2}$ alone, inoculated with one of the five isogenic bacterial strains, or left untreated. Rosette tissues from all plants in a pot were harvested as a single pool $14 \mathrm{~h}$ after inoculation. For each chip hybridization, RNA samples were pooled by equal RNA mass from three equivalently treated sets of plants taken from plant blocks grown in separate controlled environment chambers. Each chip hybridization experiment was repeated subsequently using entirely independent RNA samples from a pool of three additional plant sets grown roughly 4 months after the first plant sets. This provided two biological replicates per treatment, with each replicate monitoring RNA from three pooled sets of plants. Experiments using DC3000 and R4 were performed independently. The same growth conditions (soil type, potting system, environmental settings, and so on) were used for all plant sets and all sets were treated at the same time of day using the same pathogen inoculation protocol.

\section{Plant inoculation.}

Details of the experimental procedure are available in the electronic supplement. In brief, the wild-type Arabidopsis Col0 accession was grown for 5 to 6 weeks at $22^{\circ} \mathrm{C}$ with lights on from 9:00 a.m. to 6:00 p.m. (16 seeds per 9-cm pot). P. syringae pv. glycinea strain R4 and $P$. syringae pv. tomato strain DC3000 carried the plasmid $p V S P 61$ with no insert or with avrRpt2, avrRpm1, avrPphB, or avrRps4 under control of their native promoters (Hinsch and Staskawicz 1996; Innes et al. 1993; Kunkel et al. 1993; Simonich and Innes 1995). Bacteria were resuspended in $10 \mathrm{mM} \mathrm{MgCl}$ at $1 \times 10^{5} \mathrm{CFU} / \mathrm{ml}$ within $30 \mathrm{~min}$ before use in vacuum infiltration (at 8:30 to 8:50 a.m.), and plants were returned to their original growth chambers. Fourteen hours after treatment (10:30 to 10:50 p.m.), rosette leaves were collected by cutting with a razor at the basal stem, immediately frozen in liquid $\mathrm{N}_{2}$, and stored at $-80^{\circ} \mathrm{C}$.
RNA isolation and synthesis of biotin-labeled cRNA.

Total RNA was isolated from the plants collected from each pot using TRIzol reagent (Invitrogen, Carlsbad, CA, U.S.A.). Equal amounts of total RNA from each of the three replications of each treatment were pooled and then further purified using a QIAGEN RNeasy mini kit (Qiagen, Valencia, CA, U.S.A.). Double-stranded cDNA was synthesized according to the Affymetrix GeneChip expression analysis technical manual (Affymetrix, Inc., Santa Clara, CA, U.S.A.) using purified total RNA and the Superscript Choice system (Gibco BRL, Gaithersburg, MD, U.S.A.) with a T7-(dT) ${ }_{24}$ primer containing a T7 RNA polymerase promoter site (Genset, La Jolla, CA, U.S.A.). Biotinylated complementary RNA (cRNA) was made from the above cDNA using the ENZO BioArray HighYield RNA transcript labeling kit (ENZO, New York) and then fragmented to approximately 35 to 200 nucleotides according to the Affymetrix manual.

\section{Array hybridization, washing, staining, scanning, and initial data analysis.}

Fragmented biotin-cRNA $(15 \mu \mathrm{g})$ with manufacturer-recommended controls and spikes were hybridized to an Affymetrix GeneChip Arabidopsis AG1 genome array (Affymetrix, Inc.) for $16 \mathrm{~h}$ at $45^{\circ} \mathrm{C}$ with constant rotation at $60 \mathrm{rpm}$. Chips were washed and stained using the Affymetrix protocol on an Affymetrix fluidics station. Chips were scanned with an HP argonion laser confocal microscope, with a 488-nm emission and detection at $570 \mathrm{~nm}$. Raw fluorescent signals corresponding to hybridization intensities were analyzed with the Affymetrix Microarray Suite (MAS) 4.0 software (Affymetrix). The output from all the hybridizations was scaled globally ("Global Scaling") so that its average intensity was equal to an arbitrary target intensity of 1,500 to allow direct comparison between different treatments. MAS software also was used to calculate average difference, the primary measure of mRNA abundance (Avg Diff), difference call (Diff Call), fold change, presence call, and other available parameters. Additional analyses used GeneSpring (v. 4.0.4; Silicon Genetics, Redwood City, CA, U.S.A.) and dChip ( $\beta$-test version; Li and Wong 2001). The Methods Supplement published online contains further details.

\section{RT-PCR.}

Total RNA was extracted using the RNeasy Plant Mini Kit (Qiagen). Contaminating DNA was removed using the RNAseFree DNase Set (Qiagen). First-strand cDNA was synthesized from DNase-treated RNA using SuperScript III Reverse Transcriptase (Invitrogen). PCR reactions contained the first-strand cDNA template and corresponding gene-specific primer pairs 5'-ATATGCGTCACTGCACGAAG-3' and 5'-GGTAGACAG TGAGGTCATGAGCC-3' (for PARG/At2g31865), 5'-ATGG GTACTAGAGCTCAGCAGAT-3' and 5'-GAGAGAAGCAGA GGCTTGGTCAC-3' (for NUDT7), 5'-GCCTCTCTCTATCTG GCCTCTTGAC-3' and 5'-AGGGCAGCTCTCTGGTCTCGA GTCC-3' (for TIR1), 5'-ATGGACGAAGGAGACCTAG-3' and 5'-CTTTTCTTTGATTTGGATTCTG-3' (for WRKY29), 5'-C ACATAATTCCCACGAGGATC-3' and 5'-GTAGGTGCTC TTGTTCTTCCC-3' (for $P R-1$ ), and 5'-AGGTTCTGTTCCA GCCATC-3' and 5'-TTAGAAGCATTTCCTGTGAAC-3' (for Actin-2).

\section{Knockout lines, bacterial growth assays, and HR assays.}

Homozygous SALK T-DNA knockout lines for each of the selected genes were identified as described (Alonso et al. 2003). The nudt7-1 mutant allele corresponds to SALK_04461 and nudt7-2 mutant allele corresponds to SALK_104293. Bacterial growth within leaves was quantified 3 days after inoculation using standard procedures as described in the figure leg- 
end and by Suarez-Rodriguez and associates (2007). In all but one case, leaf punches from four leaves were pooled and tested by dilution plating for each data point, with four data points per treatment in each experiment. The HR was quantified as described in the figure legend and by Suarez-Rodriguez and associates (2007).

\section{Seedling growth inhibition assays.}

Flg22-induced seedling growth inhibition assays (GomezGomez et al. 1999) were performed as described (Pfund et al. 2004). Briefly, approximately 10 Arabidopsis seedlings per treatment were grown on $0.5 \times$ Murashige-Skoog (MS) agar media supplemented with $2 \%(\mathrm{wt} / \mathrm{vol})$ sucrose and $1 \times$ Gamborg's vitamins for 5 days and then transferred to 24-well plates ( 1 seedling per well) containing $400 \mu \mathrm{l}$ of liquid $0.5 \times$ MS salts, 2\% (wt/vol) sucrose, and 1× Gamborg's vitamins media. Seedlings were then treated as described and fresh weight was recorded 2 weeks later.

\section{Callose deposition.}

Approximately six Arabidopsis seedlings per treatment were grown on $0.5 \times \mathrm{MS}, 2 \%$ (wt/vol) sucrose, and $1 \times$ Gamborg's vitamins media for 7 days and then transferred to 24-well plates (one seedling per well) containing $400 \mu \mathrm{l}$ of liquid $0.5 \times$ MS salts, 2\% (wt/vol) sucrose, and $1 \times$ Gamborg's vitamins media. Seedlings were then treated as described. At $24 \mathrm{~h}$ after final treatment, seedlings were fixed overnight in $1 \%$ (vol/vol) glutaraldehyde, $5 \mathrm{mM}$ citric acid, and $90 \mathrm{mM} \mathrm{Na}_{2} \mathrm{HPO}_{4}(\mathrm{pH}$ 7.4) and then cleared and dehydrated with $100 \%$ ethanol. Callose was visualized using ultraviolet epifluorescence microscopy as described (Gomez-Gomez et al. 1999). Independent experiments were performed three times with similar results.

\section{ACKNOWLEDGMENTS}

This project was supported by National Science Foundation award number 9975971 to R. W. Michelmore and A. F. Bent and a Ruth L. Kirschstein National Research Service Award National Institutes of Health postdoctoral fellowship to L. Adams-Phillips. We thank S. Splinter (Gene Expression Center, University of Wisconsin-Madison) for performing microarray hybridizations and R. Doerge and $\mathrm{H}$. Jiang for substantial contributions to the ANOVA analysis.

\section{LITERATURE CITED}

Abruzzo, L. V., Wang, J., Kapoor, M., Medeiros, L. J., Keating, M. J., Edward Highsmith, W., Barron, L. L., Cromwell, C. C., and Coombes, K. R. 2005. Biological validation of differentially expressed genes in chronic lymphocytic leukemia identified by applying multiple statistical methods to oligonucleotide microarrays. J. Mol. Diagn. 7:337-345.

Alfano, J. R., and Collmer, A. 2004. Type III secretion system effector proteins: Double agents in bacterial disease and plant defense. Annu. Rev. Phytopathol. 42:385-414.

Alonso, J. M., Stepanova, A. N., Leisse, T. J., Kim, C. J., Chen, H., Shinn, P., Stevenson, D. K., Zimmerman, J., Barajas, P., Cheuk, R., Gadrinab, C., Heller, C., Jeske, A., Koesema, E., Meyers, C. C., Parker, H., Prednis, L., Ansari, Y., Choy, N., Deen, H., Geralt, M., Hazari, N., Hom, E., Karnes, M., Mulholland, C., Ndubaku, R., Schmidt, I., Guzman, P., Aguilar-Henonin, L., Schmid, M., Weigel, D., Carter, D. E., Marchand, T., Risseeuw, E., Brogden, D., Zeko, A., Crosby, W. L., Berry, C. C., and Ecker, J. R. 2003. Genome-wide insertional mutagenesis of Arabidopsis thaliana. Science 301:653-657.

Amor, Y., Babiychuk, E., Inzé, D., and Levine, A. 1998. The involvement of poly(ADP-ribose) polymerase in the oxidative stress responses in plants. FEBS (Fed. Eur. Biochem. Soc.) Lett. 440:1-7.

Asai, T., Tena, G., Plotnikova, J., Willmann, M. R., Chiu, W. L., GomezGomez, L., Boller, T., Ausubel, F. M., and Sheen, J. 2002. MAP kinase signaling cascade in Arabidopsis innate immunity. Nature 415:977-983.

Banasik, M., Komura, H., Shimoyama, M., and Ueda, K. 1992. Specific inhibitors of poly(ADP-ribose) synthetase and mono(ADP-ribosyl) transferase. J. Biol. Chem. 267:1569-1575.

Bartsch, M., Gobbato, E., Bednarek, P., Debey, S., Schultze, J. L., Bautor,
J., and Parker, J. E. 2006. Salicylic acid-independent ENHANCED DISEASE SUSCEPTIBILITY1 signaling in Arabidopsis immunity and cell death is regulated by the monooxygenase FMO1 and the Nudix hydrolase NUDT7. Plant Cell 18:1038-1051.

Bent, A. F., and Mackey, D. 2007. Elicitors, effectors and $R$ genes: The new paradigm and a lifetime supply of questions. Annu. Rev. Phytopathol. 45:399-436.

Bent, A. F., Kunkel, B. N., Dahlbeck, D., Brown, K. L., Schmidt, R. L., Giraudat, J., Leung, J. L., and Staskawicz, B. J. 1994. RPS2 of Arabidopsis thaliana: A leucine-rich repeat class of plant disease resistance genes. Science 265:1856-1860.

Berglund, T., Kalbin, G., Strid, A., Rydstrom, J., and Ohlsson, A. B. 1996. UV-B- and oxidative stress-induced increase in nicotinamide and trigonelline and inhibition of defensive metabolism induction by poly(ADP-ribose)polymerase inhibitor in plant tissue. FEBS (Fed. Eur. Biochem. Soc.) Lett. 380:188-193.

Burkle, A. 2005. Poly(ADP-ribose). The most elaborate metabolite of NAD+. FEBS (Fed. Eur. Biochem. Soc.) J. 272:4576-4589.

Century, K. S., Holub, E. B., and Staskawicz, B. J. 1995. NDR1, a locus of Arabidopsis thaliana that is required for disease resistance to both a bacterial and a fungal pathogen. Proc. Natl. Acad. Sci. U.S.A. 92:65976601.

Chinchilla, D., Zipfel, C., Robatzek, S., Kemmerling, B., Nurnberger, T., Jones, J. D., Felix, G., and Boller, T. 2007. A flagellin-induced complex of the receptor FLS2 and BAK1 initiates plant defence. Nature 448:497-500.

Chisholm, S. T., Coaker, G., Day, B., and Staskawicz, B. J. 2006. Hostmicrobe interactions: Shaping the evolution of the plant immune response. Cell 124:803-814.

Conrath, U., Beckers, G. J., Flors, V., Garcia-Agustin, P., Jakab, G., Mauch, F., Newman, M. A., Pieterse, C. M., Poinssot, B., Pozo, M. J., Pugin, A., Schaffrath, U., Ton, J., Wendehenne, D., Zimmerli, L., and Mauch-Mani, B. 2006. Priming: Getting ready for battle. Mol. PlantMicrobe Interact. 19:1062-1071.

Cuppels, D. A. 1986. Generation and characterization of Tn5 insertion mutations in Pseudomonas syringae pv. tomato. Appl. Environ. Microbiol. 51:323-327.

Dangl, J. L., and Jones, J. D. 2001. Plant pathogens and integrated defence responses to infection. Nature 411:826-833.

Debener, T., Lehnackers, H., Arnold, M., and Dangl, J. 1991. Identification and molecular mapping of a single Arabidopsis thaliana locus determining resistance to a phytopathogenic Pseudomonas syringae isolate. Plant J. 1:289-302.

De Block, M., Verduyn, C., De Brouwer, D., and Cornelissen, M. 2005. Poly(ADP-ribose) polymerase in plants affects energy homeostasis, cell death and stress tolerance. Plant J. 41:95-106.

Desprez, T., Vernhettes, S., Fagard, M., Refregier, G., Desnos, T., Aletti, E., Py, N., Pelletier, S., and Hofte, H. 2002. Resistance against herbicide isoxaben and cellulose deficiency caused by distinct mutations in same cellulose synthase isoform CESA6. Plant Physiol. 128:482-490.

Dong, X., Mindrinos, M., Davis, K. R., and Ausubel, F. M. 1991. Induction of Arabidopsis thaliana defense genes by virulent and avirulent Pseudomonas syringae strains and by a cloned avirulence gene. Plant Cell 3:61-72.

Dunning, F. M., Sun, W., Jansen, K. L., Helft, L., and Bent, A. F. 2007. Identification and mutational analysis of Arabidopsis FLS2 leucine-rich repeat domain residues that contribute to flagellin perception. Plant Cell. 19:3297-3313.

Eulgem, T., Weigman, V. J., Chang, H. S., McDowell, J. M., Holub, E. B., Glazebrook, J., Zhu, T., and Dangl, J. L. 2004. Gene expression signatures from three genetically separable resistance gene signaling pathways for downy mildew resistance. Plant Physiol. 135:1129-1144.

Felix, G., Duran, J. D., Volko, S., and Boller, T. 1999. Plants have a sensitive perception system for the most conserved domain of bacterial flagellin. Plant J. 18:265-276.

Feys, B. J., and Parker, J. E. 2000. Interplay of signaling pathways in plant disease resistance. Trends Genet. 16:449-455.

Gagne, J. P., Hendzel, M. J., Droit, A., and Poirier, G. G. 2006. The expanding role of poly(ADP-ribose) metabolism: Current challenges and new perspectives. Curr. Opin. Cell Biol. 18:145-151.

Gassmann, W., Hinsch, M. E., and Staskawicz, B. J. 1999. The Arabidopsis RPS4 bacterial-resistance gene is a member of the TIR-NBS-LRR family of disease-resistance genes. Plant J. 20:265-277.

Ge, X., Li, G. J., Wang, S. B., Zhu, H., Zhu, T., Wang, X., and Xia, Y. 2007. AtNUDT7, a negative regulator of basal immunity in Arabidopsis, modulates two distinct defense response pathways and is involved in maintaining redox homeostasis. Plant Physiol. 145:204-215.

Glazebrook, J. 2001. Genes controlling expression of defense responses in Arabidopsis-2001 status. Curr. Opin. Plant Biol. 4:301-308.

Glazebrook, J., Rogers, E. E., and Ausubel, F. M. 1996. Isolation of Arabi- 
dopsis mutants with enhanced disease susceptibility by direct screening. Genetics 143:973-982.

Gomez-Gomez, L., and Boller, T. 2000. FLS2: An LRR receptor-like kinase involved in the perception of the bacterial elicitor flagellin in Arabidopsis. Mol. Cell 5:1003-1011.

Gomez-Gomez, L., Felix, G., and Boller, T. 1999. A single locus determines sensitivity to bacterial flagellin in Arabidopsis thaliana. Plant J. 18:277-284

Grant, M. R., Godiard, L., Straube, E., Ashfield, T., Lewald, J., Sattler, A., Innes, R. W., and Dangl, J. L. 1995. Structure of the Arabidopsis RPMI gene enabling dual specificity disease resistance. Science 269:843-846.

Guzman, P., and Ecker, J. R. 1990. Exploiting the triple response of Arabidopsis to identify ethylene-related mutants. Plant Cell 2:513-523.

Hammond-Kosack, K. E., and Parker, J. E. 2003. Deciphering plant-pathogen communication: Fresh perspectives for molecular resistance breeding. Curr. Opin. Biotechnol. 14:177-193.

Hinsch, M., and Staskawicz, B. 1996. Identification of a new Arabidopsis disease resistance locus, RPS4, and cloning of the corresponding avirulence gene, avrRps4, from Pseudomonas syringae pv. pisi. Mol. PlantMicrobe Interact. 9:55-61.

Hunt, L., Lerner, F., and M., Z. 2004. NAD-new roles in signaling and gene regulation in plants. New Phytol. 163:31-44.

Hunting, D. J., Gowans, B. J., and Henderson, J. F. 1985. Specificity of inhibitors of poly(ADP-ribose) synthesis. Effects on nucleotide metabolism in cultured cells. Mol. Pharmacol. 28:200-206.

Innes, R. W., Bisgrove, S. R., Smith, N. M., Bent, A. F., Staskawicz, B. J., and Liu, Y.-C. 1993. Identification of a disease resistance locus in Arabidopsis that is functionally homologous to the Rpgl locus of soybean. Plant J. 4:813-820.

Jagtap, P., and Szabo, C. 2005. Poly(ADP-ribose) polymerase and the therapeutic effects of its inhibitors. Nat. Rev. Drug Discov. 4:421-440.

Jambunathan, N., and Mahalingam, R. 2006. Analysis of Arabidopsis growth factor gene 1 (GFG1) encoding a nudix hydrolase during oxidative signaling. Planta 224:1-11.

Jeffery, I. B., Higgins, D. G., and Culhane, A. C. 2006. Comparison and evaluation of methods for generating differentially expressed gene lists from microarray data. BMC Bioinf. 7:359.

Jenner, C., Hitchin, E., Mansfield, J., Walters, K., Betteridge, P., Teverson, D., and Taylor, J. 1991. Gene-for-gene interactions between Pseudomonas syringae pv. phaseolicola and Phaseolus. Mol. Plant-Microbe Interact. 4:553-562.

Jones, J. D., and Dangl, J. L. 2006. The plant immune system. Nature 444:323-329.

Kannangara, R., Branigan, C., Liu, Y., Penfield, T., Rao, V., Mouille, G., Hofte, H., Pauly, M., Riechmann, J. L., and Broun, P. 2007. The transcription factor WIN1/SHN1 regulates Cutin biosynthesis in Arabidopsis thaliana. Plant Cell 19:1278-1294.

Koh, D. W., Lawler, A. M., Poitras, M. F., Sasaki, M., Wattler, S., Nehls, M. C., Stoger, T., Poirier, G. G., Dawson, V. L., and Dawson, T. M. 2004. Failure to degrade poly(ADP-ribose) causes increased sensitivity to cytotoxicity and early embryonic lethality. Proc. Natl. Acad. Sci. U.S.A. 101:17699-17704.

Kunkel, B. N., Bent, A. F., Dahlbeck, D., Innes, R. W., and Staskawicz, B. J. 1993. RPS2, an Arabidopsis disease resistance locus specifying recognition of Pseudomonas syringae strains expressing the avirulence gene avrRpt2. Plant Cell 5:865-875.

Li, C. and Wong, W.H. 2001. Model-based analysis of oligonucleotide arrays: expression index computation and outlier detection. Proc. Natl. Acad. Sci. U.S.A. 98:31-36.

Lucas, J. A. 1998. Plant Pathology and Plant Pathogens. Blackwell Science, Oxford, U.K. (Malden, MA, U.S.A.).

Martin, G. B., Bogdanove, A. J., and Sessa, G. 2003. Understanding the functions of plant disease resistance proteins. Annu. Rev. Plant Biol. 54:23-61.

McDowell, J. M., Cuzick, A., Can, C., Beynon, J., Dangl, J. L., and Holub, E. B. 2000. Downy mildew (Peronospora parasitica) resistance genes in Arabidopsis vary in functional requirements for NDR1, EDS1, NPR1 and salicylic acid accumulation. Plant J 22:523-529.

McIntosh, R. A., Wellings, C. R., and Park, R. F. 1995. Wheat Rusts: An Atlas of Resistance Genes. CSIRO Australia and Kluwer Academic Publishers, Dordrecht, The Netherlands.

Meyers, B. C., Kozik, A., Griego, A., Kuang, H., and Michelmore, R. W. 2003. Genome-wide analysis of NBS-LRR-encoding genes in Arabidopsis. Plant Cell 15:809-834.

Michelmore, R. 2000. Genomic approaches to plant disease resistance. Curr. Opin. Plant Biol. 3:125-131.

Millenaar, F. F., Okyere, J., May, S. T., van Zanten, M., Voesenek, L. A., and Peeters, A. J. 2006. How to decide? Different methods of calculating gene expression from short oligonucleotide array data will give different results. BMC Bioinf. 7:137.
Mindrinos, M., Katagiri, F., Yu, G.-L., and Ausubel, F. M. 1994. The $A$ thaliana disease resistance gene RPS2 encodes a protein containing a nucleotide-binding site and leucine-rich repeats. Cell 78:1089-1099.

Minsavage, G., Dahlbeck, D., Whalen, M., Kearney, B., Bonas, U., Staskawicz, B. J., and Stall, R. E. 1990. Gene-for-gene relationships specifying disease resistance in Xanthomonas campestris pv. vesicato ria-pepper interactions. Mol. Plant-Microbe Interact. 3:41-47.

Nadon, R., and Shoemaker, J. 2002. Statistical issues with microarrays: Processing and analysis. Trends Genet. 18:265-271.

Navarro, L., Zipfel, C., Rowland, O., Keller, I., Robatzek, S., Boller, T., and Jones, J. D. 2004. The transcriptional innate immune response to flg22. Interplay and overlap with Avr gene-dependent defense responses and bacterial pathogenesis. Plant Physiol. 135:1113-1128.

Navarro, L., Dunoyer, P., Jay, F., Arnold, B., Dharmasiri, N., Estelle, M., Voinnet, O., and Jones, J. D. 2006. A plant miRNA contributes to antibacterial resistance by repressing auxin signaling. Science 312:436-439.

Oei, S. L., Keil, C., and Ziegler, M. 2005. Poly(ADP-ribosylation) and genomic stability. Biochem. Cell Biol. 83:263-269.

Ogawa, T., Ueda, Y., Yoshimura, K., and Shigeoka, S. 2005. Comprehensive analysis of cytosolic Nudix hydrolases in Arabidopsis thaliana. J. Biol. Chem. 280:25277-25283.

Olejnik, K., and Kraszewska, E. 2005. Cloning and characterization of an Arabidopsis thaliana Nudix hydrolase homologous to the mammalian GFG protein. Biochim. Biophys. Acta 1752:133-141.

Panda, S., Poirier, G. G., and Kay, S. A. 2002. tej defines a role for poly(ADP-ribosyl)ation in establishing period length of the Arabidopsis circadian oscillator. Dev. Cell 3:51-61.

Pfund, C., Tans-Kersten, J., Dunning, F. M., Alonso, J. M., Ecker, J. R., Allen, C., and Bent, A. F. 2004. Flagellin is not a major defense elicitor in Ralstonia solanacearum cells or extracts applied to Arabidopsis thaliana. Mol. Plant-Microbe Interact. 17:696-706.

Purnell, M. R., and Whish, W. J. 1980. Novel inhibitors of poly(ADPribose) synthetase. Biochem. J. 185:775-777.

Rankin, P. W., Jacobson, E. L., Benjamin, R. C., Moss, J., and Jacobson, M. K. 1989. Quantitative studies of inhibitors of ADP-ribosylation in vitro and in vivo. J. Biol. Chem. 264:4312-4317.

Ritter, C., and Dangl, J. L. 1996. Interference between two specific pathogen recognition events mediated by distinct plant disease resistance genes. Plant Cell 8:251-257.

Sato, M., Mitra, R. M., Coller, J., Wang, D., Spivey, N. W., Dewdney, J., Denoux, C., Glazebrook, J., and Katagiri, F. 2007. A high-performance, small-scale microarray for expression profiling of many samples in Arabidopsis-pathogen studies. Plant J. 49:565-577.

Scheible, W. R., Eshed, R., Richmond, T., Delmer, D., and Somerville, C. 2001. Modifications of cellulose synthase confer resistance to isoxaben and thiazolidinone herbicides in Arabidopsis Ixr1 mutants. Proc. Natl. Acad. Sci. U.S.A. 98:10079-10084.

Schreiber, V., Dantzer, F., Ame, J. C., and de Murcia, G. 2006. Poly(ADPribose): Novel functions for an old molecule. Nat. Rev. Mol. Cell Biol. 7:517-528.

Seifert, G. J. 2004. Nucleotide sugar interconversions and cell wall biosynthesis: How to bring the inside to the outside. Curr. Opin. Plant Biol 7:277-284.

Shedden, K., Chen, W., Kuick, R., Ghosh, D., Macdonald, J., Cho, K. R., Giordano, T. J., Gruber, S. B., Fearon, E. R., Taylor, J. M., and Hanash, S. 2005. Comparison of seven methods for producing Affymetrix expression scores based on False Discovery Rates in disease profiling data. BMC Bioinf. 6:26.

Shen, Q. H., Saijo, Y., Mauch, S., Biskup, C., Bieri, S., Keller, B., Seki, H., Ulker, B., Somssich, I. E., and Schulze-Lefert, P. 2006. Nuclear activity of MLA immune receptors links isolate-specific and basal disease-resistance responses. Science 315:1098-1103.

Simonich, M. T., and Innes, R. W. 1995. A disease resistance gene in Arabidopsis with specificity for the avrPph3 gene of Pseudomonas sy ringae pv. phaseolicola. Mol. Plant-Microbe Interact. 8:637-640.

Slonim, D. K. 2002. From patterns to pathways: Gene expression data analysis comes of age. Nat. Genet. (Suppl.) 32:502-508.

Smyth, G. K., Yang, Y. H., and Speed, T. 2003. Statistical issues in cDNA microarray data analysis. Methods Mol. Biol. 224:111-113.

Stafford, P., and Brun, M. 2007. Three methods for optimization of crosslaboratory and cross-platform microarray expression data. Nucleic Acids Res. 35:e72.

Suarez-Rodriguez, M. C., Adams-Phillips, L., Liu, Y., Wang, H., Su, S. H., Jester, P. J., Zhang, S., Bent, A. F., and Krysan, P. J. 2007. MEKK1 is required for flg22-induced MPK4 activation in Arabidopsis plants. Plant Physiol. 143:661-669.

Sun, W., Dunning, F. M., Pfund, C., Weingarten, R., and Bent, A. F. 2006. Within-species flagellin polymorphism in Xanthomonas campestris pv. campestris and its impact on elicitation of Arabidopsis FLAGELLIN SENSING2-dependent defenses. Plant Cell 18:764-779. 
Tao, Y., Xie, Z. Y., Chen, W. Q., Glazebrook, J., Chang, H. S., Han, B. Zhu, T., Zou, G. Z., and Katagiri, F. 2003. Quantitative nature of Arabidopsis responses during compatible and incompatible interactions with the bacterial pathogen Pseudomonas syringae. Plant Cell 15:317-330.

Turner, J. G., and Novacky, A. 1974. The quantitative relation between plant and bacterial cells involved in the hypersensitive reaction. Phytopathology 64:885-890.

Vanderauwera, S., De Block, M., Van de Steene, N., van de Cotte, B. Metzlaff, M., and Van Breusegem, F. 2007. Silencing of poly(ADP-ribose) polymerase in plants alters abiotic stress signal transduction. Proc. Natl. Acad. Sci. U.S.A. 104:15150-15155.

van Loon, L. C., Rep, M., and Pieterse, C. M. 2006. Significance of inducible defense-related proteins in infected plants. Annu. Rev. Phytopathol. 44:135-162.

Warren, R. F., Henk, A., Mowery, P., Holub, E., and Innes, R. W. 1998. A mutation within the leucine-rich repeat domain of the Arabidopsis disease resistance gene RPS5 partially suppresses multiple bacterial and downy mildew resistance genes. Plant Cell 10:1439-1452.

Whalen, M., Innes, R., Bent, A., and Staskawicz, B. 1991. Identification of Pseudomonas syringae pathogens of Arabidopsis thaliana and a bacte- rial gene determining avirulence on both Arabidopsis and soybean Plant Cell 3:49-59.

Yu, I.-c., Parker, J., and Bent, A. F. 1998. Gene-for-gene disease resistance without the hypersensitive response in Arabidopsis dndl mutant. Proc. Natl. Acad. Sci. U.S.A. 95:7819-7824.

Ziegler, M. 2000. New functions of a long-known molecule. Emerging roles of NAD in cellular signaling. Eur. J. Biochem. 267:1550-1564.

Zipfel, C., and Felix, G. 2005. Plants and animals: A different taste for microbes? Curr. Opin. Plant Biol. 8:353-360.

Zipfel, C., Kunze, G., Chinchilla, D., Caniard, A., Jones, J. D., Boller, T., and Felix, G. 2006. Perception of the bacterial PAMP EF-Tu by the receptor EFR restricts Agrobacterium-mediated transformation. Cell $125: 749-760$

\section{AUTHOR-RECOMMENDED INTERNET RESOURCES}

University of California Davis's Functional and Comparative Genomics of Disease Resistance Gene Homologs website: niblrrs.ucdavis.edu ArrayExpress website: www.ebi.ac.uk/arrayexpress 